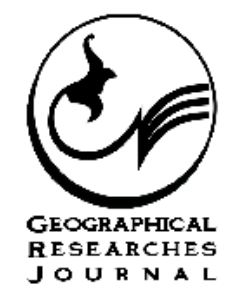

\title{
Impact Assessment of Urban Physical Development on Hydrogeomorphological Systems of Tehran Metropolis (Case study:Darband Catchment)
}

\section{ART ICLE INFO}

\section{Article Type}

Original Research

\section{Authors}

Khosravi S. ${ }^{1} M A$

Entezari M.*PhD,

Ahmad Abadi A. ${ }^{2} P h D$,

Pour Mousavi M. ${ }^{3} \mathrm{PhD}$

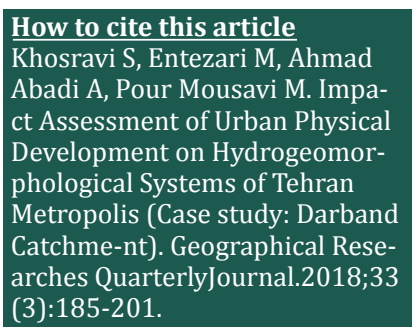

*Department of Geography, Faculty of Geographical Sciences, Isfahan, Iran

${ }^{1}$ Department of Geography, Faculty of Geographical Sciences, Isfahan, Iran

${ }^{2}$ Department of Geography, Faculty of Geographical Scineces, Kharazmi, Tehran, Iran

${ }^{3}$ Department of Geography \& Urban Planning, Scinence \& Research, Islamic Azad University, Tehran,Iran

\section{*Correspondence}

Address: Water and soil laboratory, Faculty of Geographical Sciences, Isfahan, Iran.

Phone: 03137933096

Fax: -

Entezari54@yahoo.com

\section{Article History}

Received: July 3, 2018

Accepted: October 4, 2018

ePublished: December 09, 2018

\begin{abstract}
A B S T R A C T
Introduction and Background The development of urbanization and the transformation of rural areas into cities are accompanied by land use changes and pressure on natural systems. One of the natural systems is the rivers that are affected by human activities in urban areas.

Aims The purpose of this study is simulation and estimation of the variations of geohydro-logical parameters including surface runoff, river discharge, permeability and evapotranspiration.

Methodology his research has been conducted using the semi-distributed SWAT model in the last two decades of the past twenty years (1998) and present (2018) in the catchment area of Darband. In this study, the SUFI2 algorithm was used to calibrate the model.

Conclusion The results of the research show that after optimizing the parameters used in SWAT-CUP, the value of Nash-Sutcliff (NS) and R2 coefficient of year 1998 in the calibration stage is equal to 0.34 and 0.43 , respectively, for the validation period, the coefficient value Nash-Sutcliff and the coefficient of determination are respectively 30/0 and 39/0 respectively. Also, the SWAT-CUP model was studied and evaluated in the current situation of Darband-Golad-Dare Basin for 2018. The results of observational and simulated hydrographs are presented and the performance evaluation values of the model are presented below. The value of nisoscatheff (NS) and coefficient of determination (R2) were estimated to be 0.31 and 0.46 during the calibration period, 0.33 and 0.39 , respectively, during the validation period. According to the results of the performance evaluation, the model based on Nash-Thaw (NS) coefficient and determination coefficient (R2) shows the ability of the swat model to simulate the runoff of the basin. Similarly, the simulation results show that changes in the range of the study area caused a change in $\mathrm{CN}$ values, runoff and evapotranspiration at the user level over a period of 20 years.
\end{abstract}

Keywords Darband Catchment; CN; HRU; SWAT; SUFI2

\section{I T A T I O N L I N KS}

[A Detailed Plan of the Tehran 1 Region; 2007] Department of Management and Planning of Tehran ...; [Abbaspour; 2007] User manual for SWAT-CUP, SWAT ...; [Agha Beigi \& Lesani; 2008] Runoff analysis of the city of Mashhad using ...; [Ahmad Abadi, et al.; 2017] The effects of watershed management practices ...; [Alansi, et al; 2009] Validation of SWAT model for stream flow ...; [Amani, et al.; 2006] Simulation of stream flow by applying SWAT ...; [Booth et al.; 2004] Reviving urban streams: Land use, hydrology, ...; [Chin; 2006] Urban transformation of river landscapes in ...; [Chin, et al.; 2013] 9.39 urbanization and river channels ...; [Findlay \& Taylor; 2006] Why rehabilitate urban river ...; [Ghanavati, et al.; 2016] Hydrogeomorphological characteristics of Tehran ...; [Goodarzi, et al.; 2012] Performance comparison of three hydrological ...; [Haji Hosseini, et al.; 2015] Hydrological simulation of the upper hirmand ...; [Hardison, et al; 2009] Urban land use, channel incision, and water ...; [Hossein zadeh \& Esmaeli; 2015] River geomorphology ...; [Hossein Zadeh \& Jahadi Toroghi; 2007] The effects of urbanization on the natural ...; [Hosseini et al.; 2012] Effects of land use changes on water balance in Taleghan ...; [Hosseini \& Mokarian; 2014] Estimation of ground water runoff by SWAT ...; [Lagacherie, et al.; 2008] A landscape discretization tool for distributed hydrological ...; [Lin, et al.; 2008] Monitoring and predicting land-use changes and the ...; [Mengistu; 2009] Watershed hydrological responses to changes in land ...; [Najafi; 2015] Geomorphologic modeling of bridges in ...; [Navratil, et al.; 2013] Hydrogeomorphic adjustments of stream channels ...; [Royall; 2013] Land-Use Impacts on the Hydrogeomorphology ...; [Saberi; 1995] Investigating the effects of urban development ...; [Taniguchi \& Biggs; 2015] Regional impacts of urbanization on stream channel geometry: A case ...; [Verbeeten \& Barendregt; 2007] The impacts of climate change on hydrological services ...; [Vietz, et al.; 2015] Urban hydrogeomorphology and the urban stream syndrome ...; [Zamanzadeh, et al.; 2013] Erosion of the bed and river bank due to the harvesting of river ... 
Khosravi S. MA

Entezari M. PhD

Ahmad abadi A. PhD

Pour Mousavi M. PhD

m.entezari@geo.ui.ac.ir

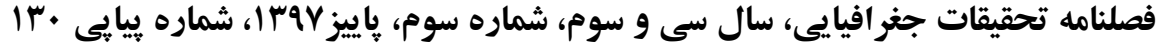

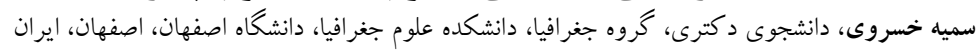

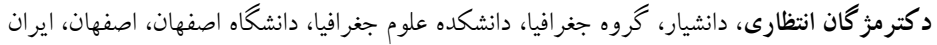

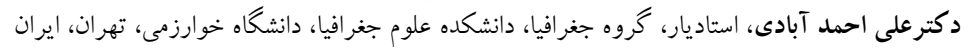

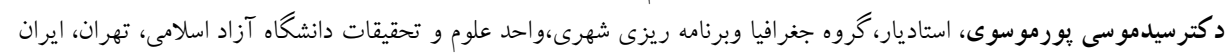

\section{ارزيابى تأثير توسعه كالبدى شهر بر سيستم هاى هيدروزئومورفولوزى كلان شهر تهران مطالعه موردى: حوزه آبريز دربند}

مقدمه: توسعه شهرنشينى و تبديل مناطق روستايى به شهرها با تغييرات كاربرى اراضى و فشار بر سيستمهاى طبيعى همراه

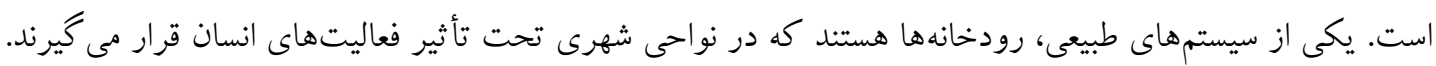

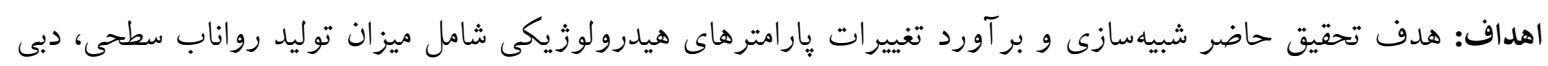
رودخانه، نفوذيذيرى و ميزان تبخير و تعرق مىباشد.

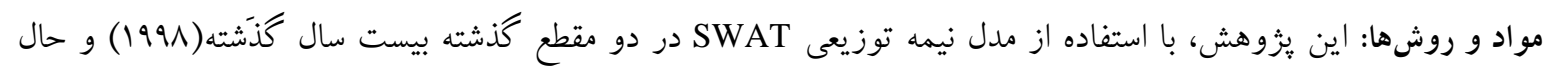

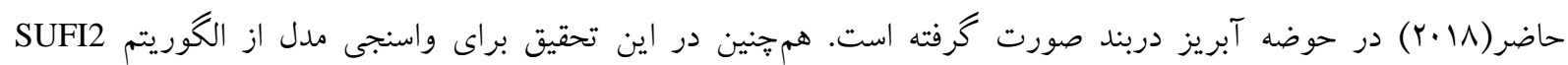
استفاده اسده است.

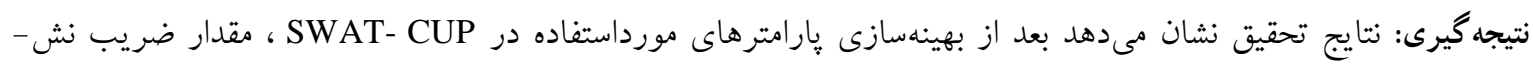

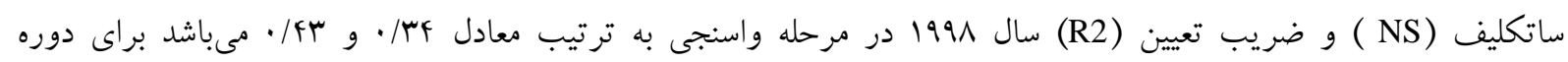

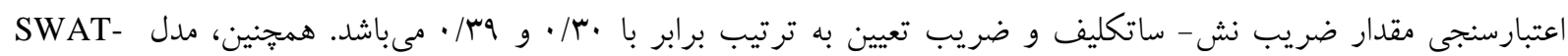

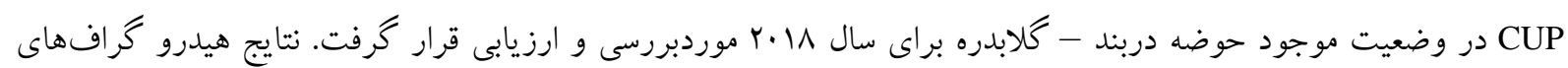

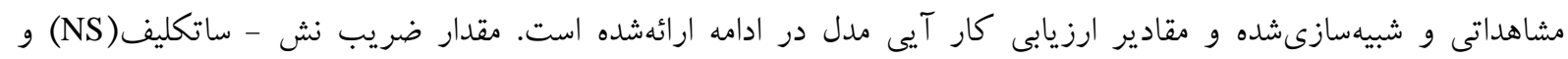

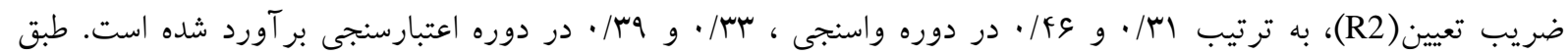

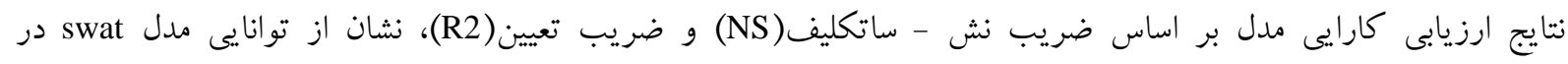
شبيهسازى رواناب حوضه دارد. همة جنين نتايج حاصل از شبيهسازى نشان مىدهد تغييرات كاربرى در محدوده موردمطالعه باعث تغيير در مقادير CN ، رواناب سطحى و تبخير و تعرق در سطح كاربرى هـا در بازه زمانى ·r ساله شده است.

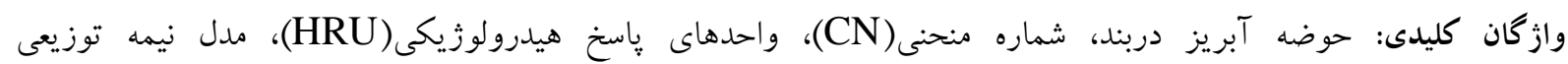

رشد سريع شهرنشينى در طى سالهاى اخير موجب گسترش شهرها مناطق مختلف جهان خصوصا كشورهاى درحال توسعه شده

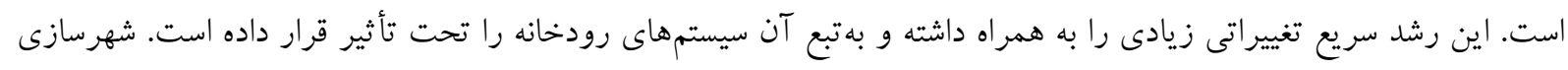


ارزيابى تاثير توسعه كالبدى شهر بر سيستم هاى ... INV I

بهصورت مستقيم و غيرمستقيم بر سيستمهاى رودخانهاى تأثير مى گذارد (Hossein zadeh \& Esmaeli, 2015). افزايش و

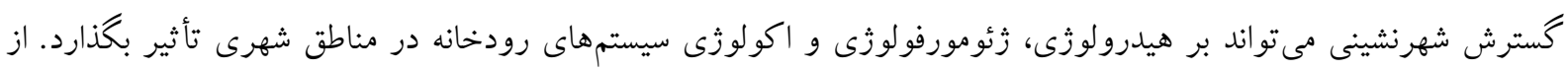

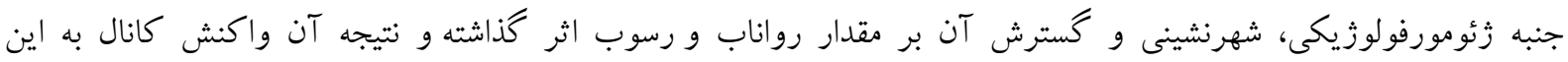

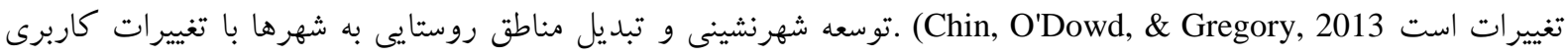
اراضى و فشار بر سيستمهاى رودخانه همراه است (Hardison, O’Driscoll, DeLoatch, Howard, \& Brinson, 2009). در

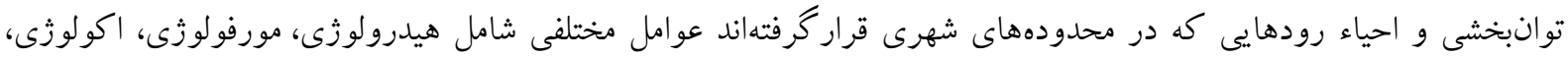

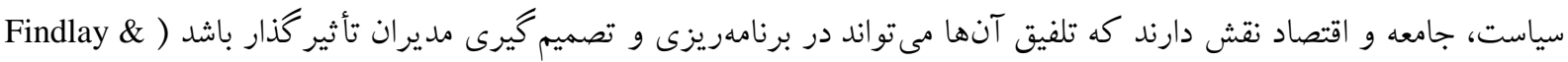

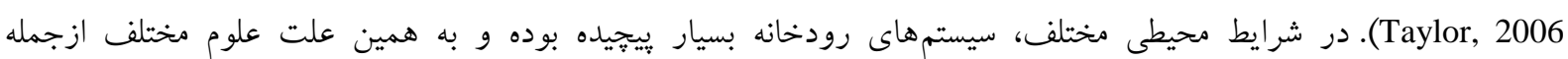
زئومورفولوزى، اين سيستمها را از جنبه هاى مختلف موردبحث و بررسى قرار دادهاند (Najafi, 2015). زئومورفولوزيستهاتها،

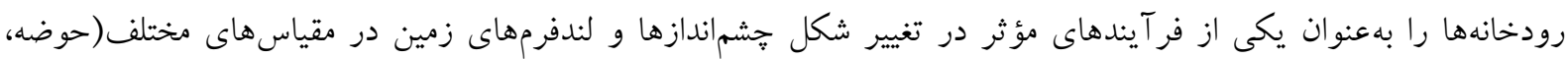

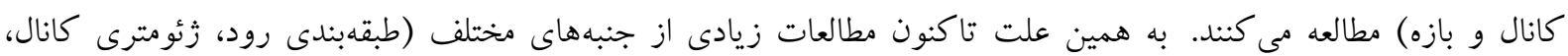
هيدروليك جريان) در خصوص رودخانهها انجام گرفته است (Zamanzadeh, Yamani, \& Bani Safar, 2013). يكى از سيستمهاى طبيعى، رودخانها هستند كه در نواحى شهرى تحت تأثير فعاليتهاى انسان قرار مى گيرند لذا، نقش انسان

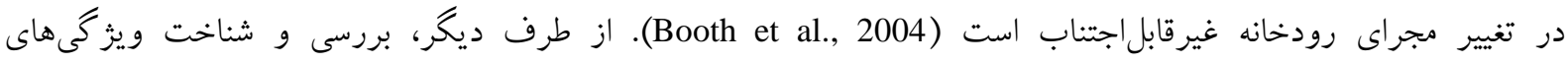

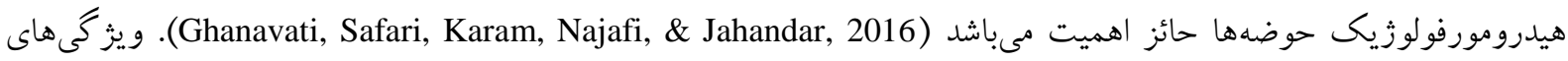

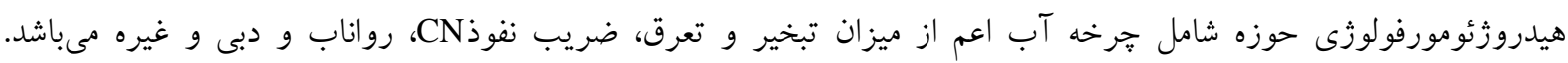

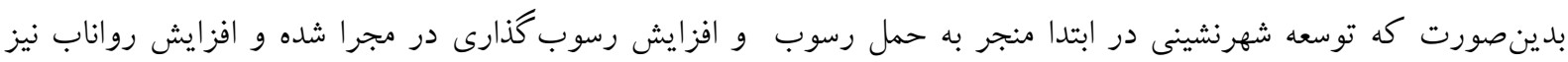

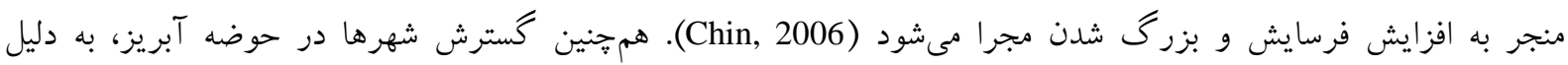

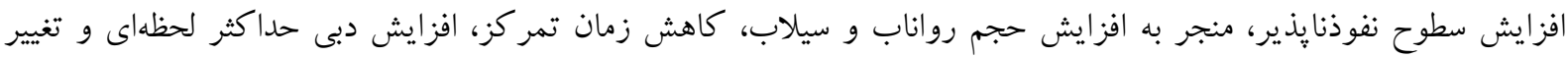

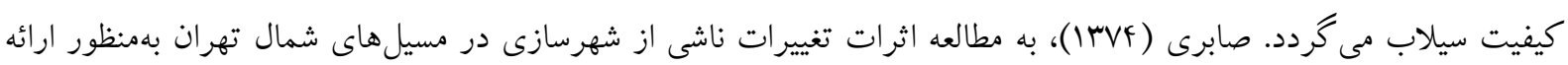

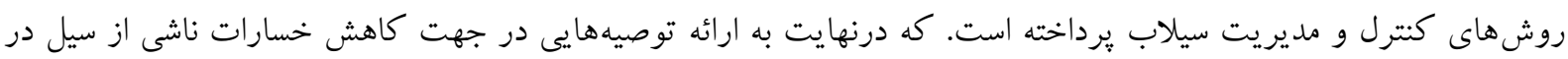

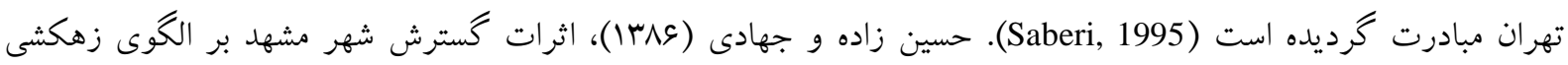

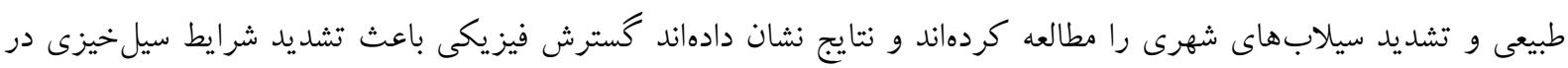
اين شهر و آسيب پيذيرى بخشهاى وسيعى از بافت آن شده است (Hossein Zadeh \& Jahadi Toroghi, 2007).

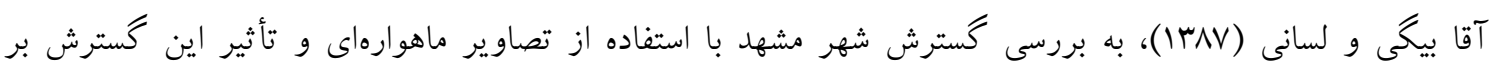

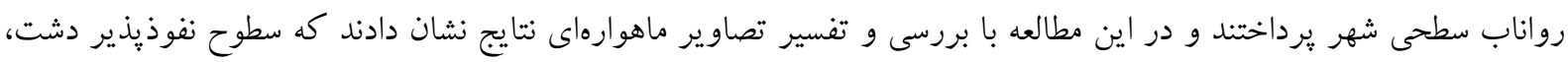
دامنهاى كم شيب ، حاشيههاى رودخانهها و اراضى كشاورزى به آسفالت خيابان و ساختمانهاى شهرى تغيير فرم داده و و

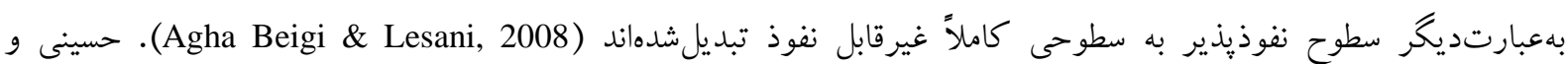

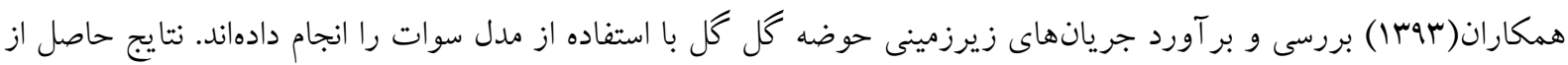

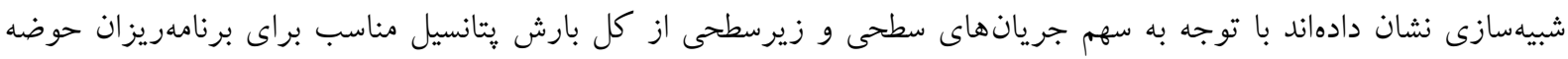

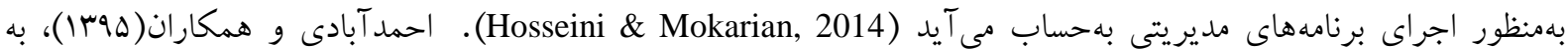
تحليل اثرات عمليات آبخيزدارى بر خصوصيات هيدروزموروفولوزيكى حوضه آبريز عنبران جائى باى با استفاده از مدل سوات

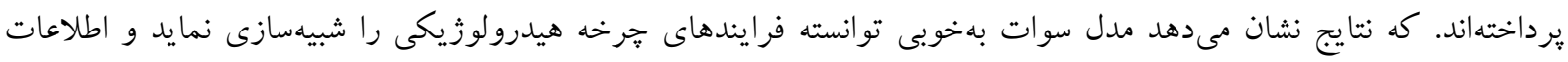

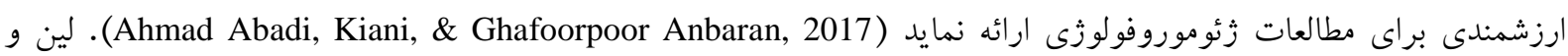




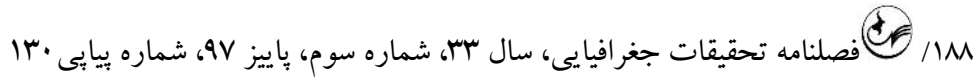
همكاران (^• (r) به بررسى تغييرات و شبيهسازى كاربرى اراضى و تأثير آن بر هيدرولوزى و رواناب سطحى شهر با استفاده از

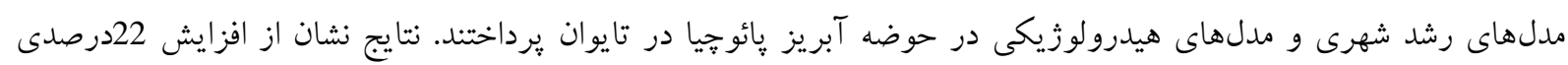
رواناب ناشى از رشد شهر مىدهند (Lin, Lin, Wang, \& Hong, 2008). هاريسون و همكاران(Y. (Y)، اثرات كاربرى اراضى شهرى را بر كانالهاى رودخانهاى و تغييرات سطح آب زيرزمينى

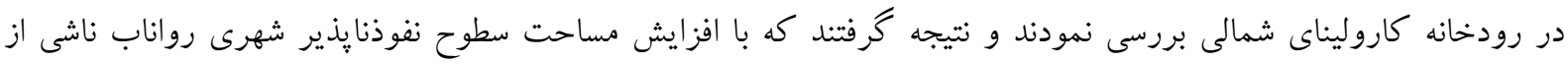

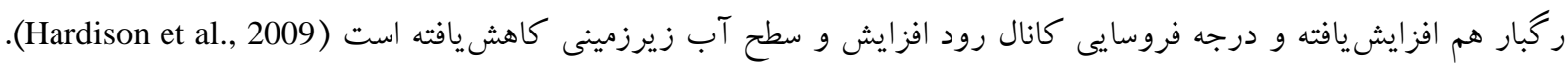

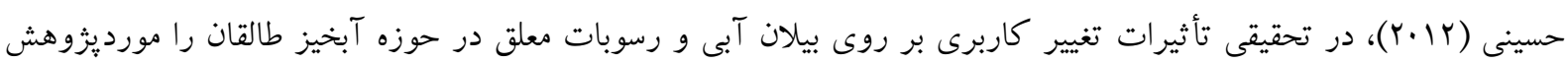

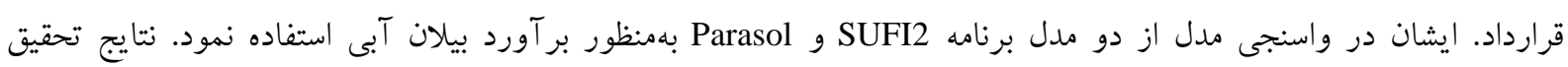

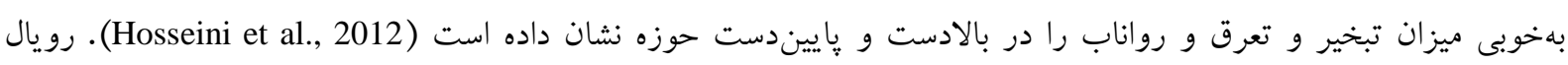

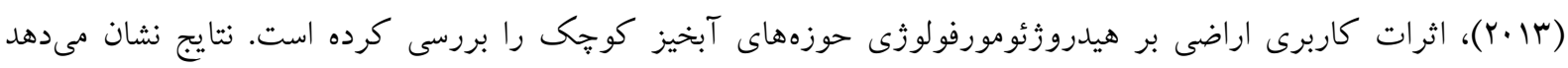

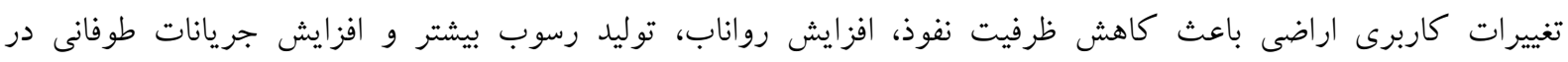

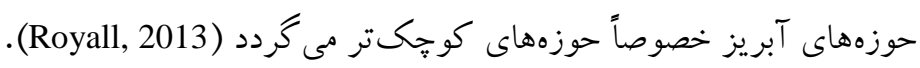

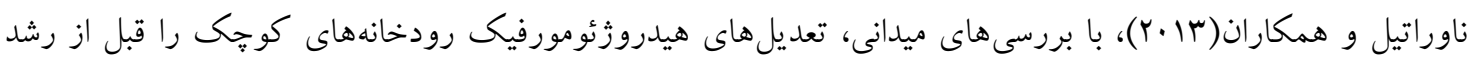

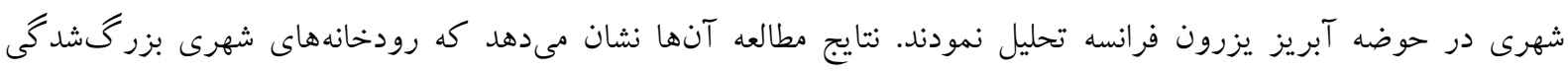

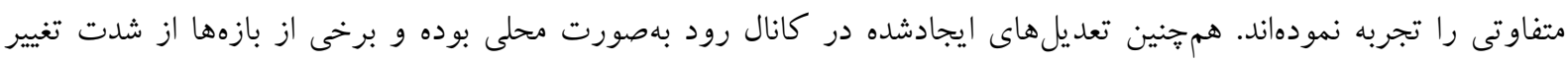
بيشترى برخوردار بوده است (Navratil, Breil, Schmitt, Grosprêtre, \& Albert, 2013).

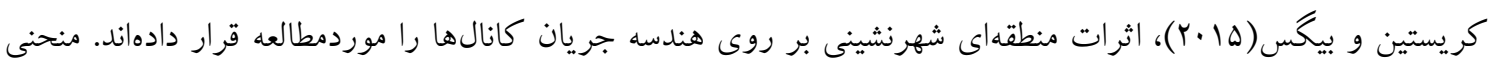

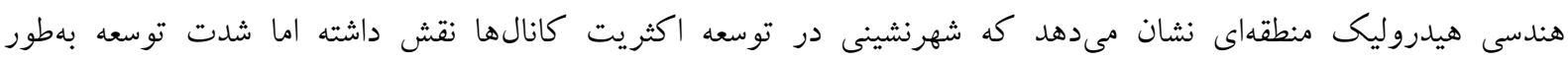
كسترداى متفاوت است (Taniguchi \& Biggs, 2015).

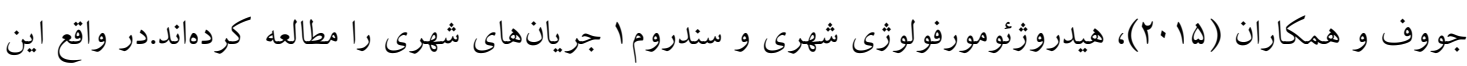

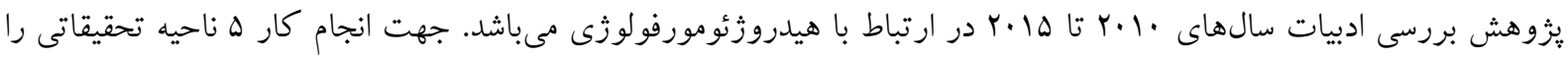

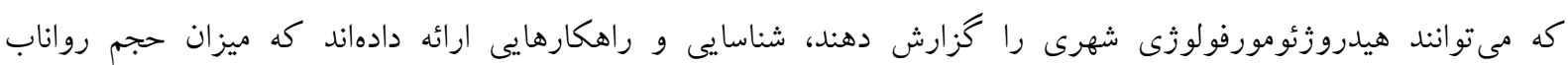
رودخانهاى شهرى را كاهش تا تأثير آن بر زئومورفولوزى جريان روزئن را تقليل دهند (Vietz, Walsh, \& Fletcher, 2015). حوضه آبريز دربند مهمترين حوضه واقع در شمال تهران مىباشند كه بخش مهمى از رواناب جارىشده بهطرف تهران

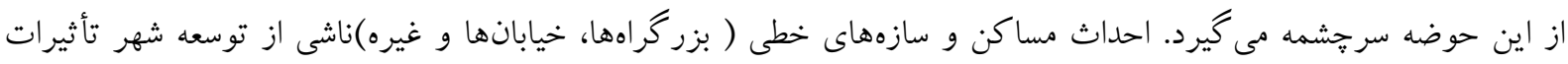

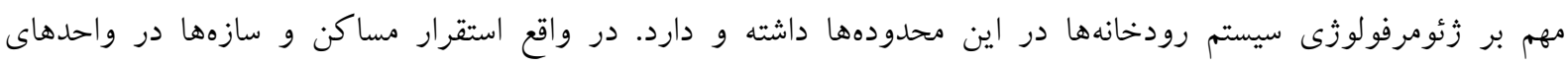

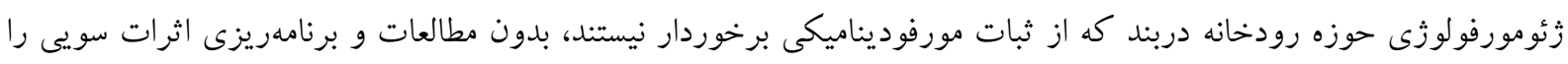

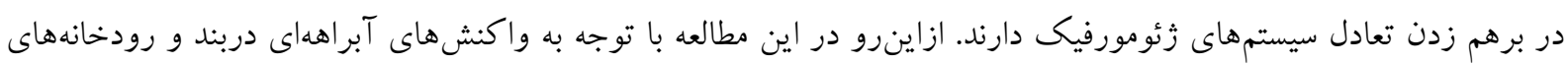

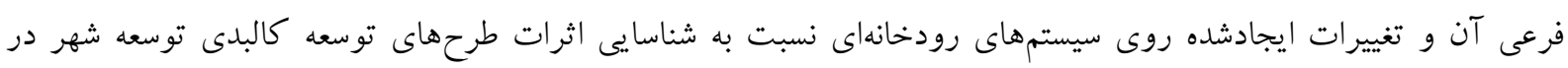

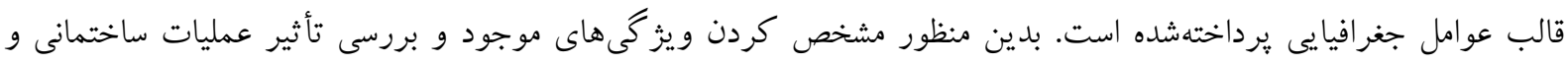

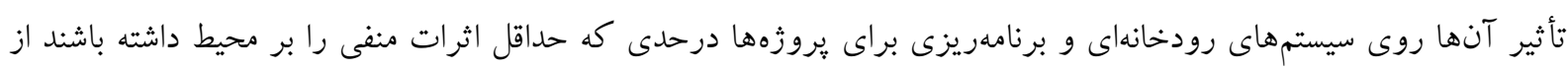

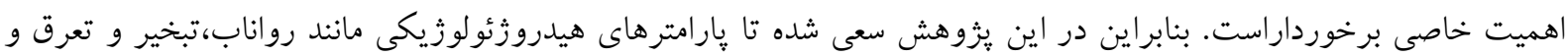




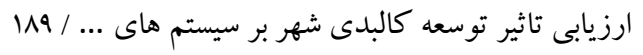

DOI: 10.29252/geores.33.3. 185

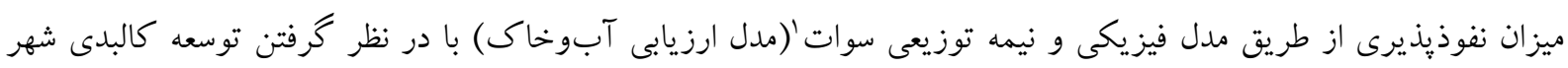

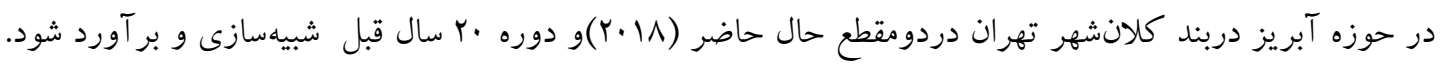

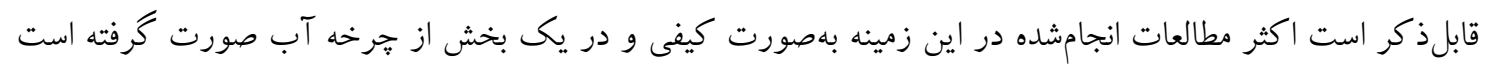

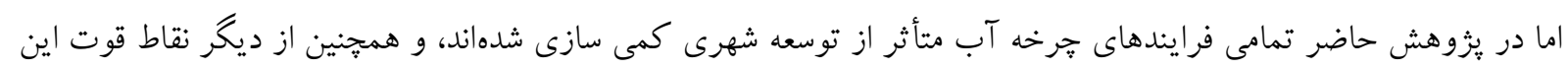

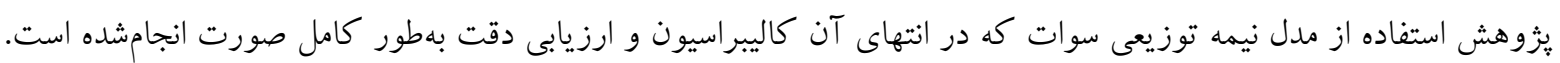

\section{محدوده موردمطالعه}

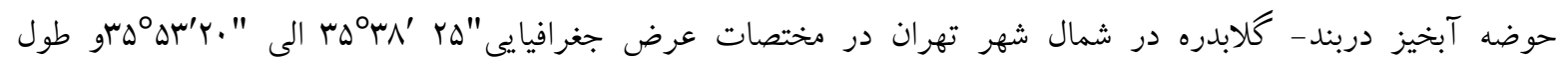

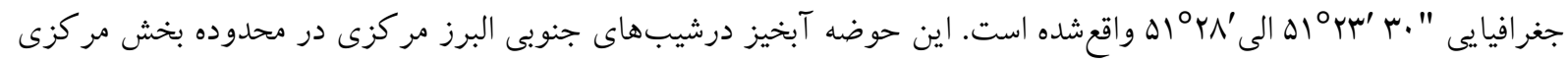

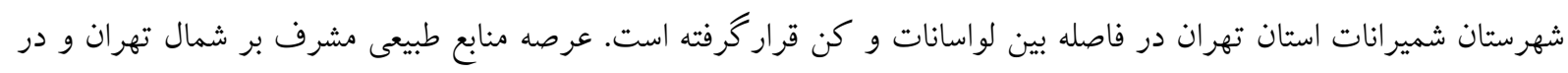

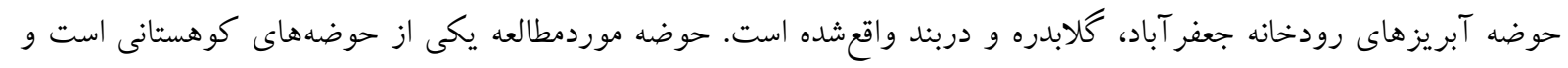

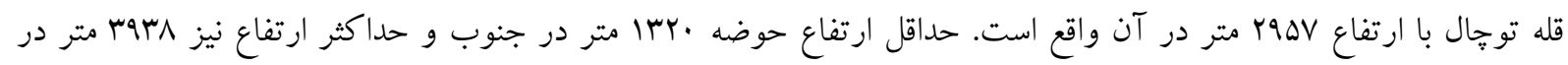

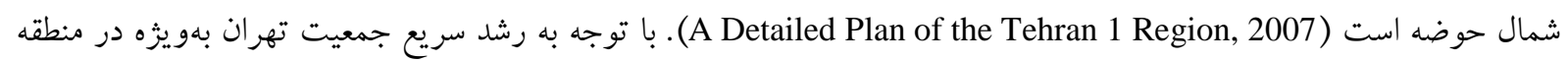

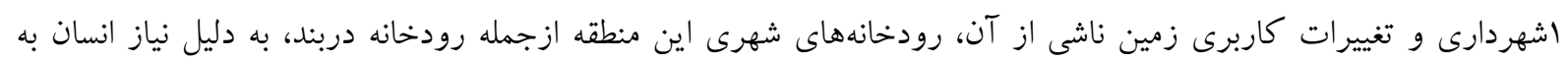
فضاى زيست در معرض آسيب و تجاوز به حريم بوده است.

جدول 1- مشخصات فيزيوكر افى حوضه موردمطالعه

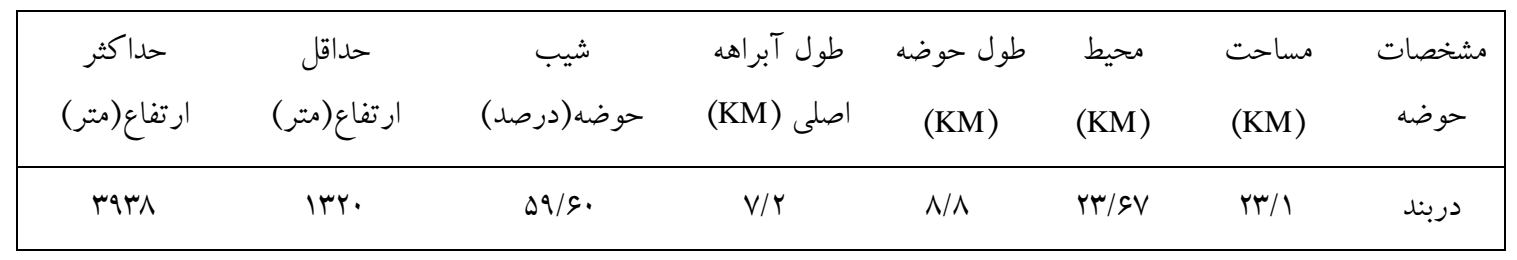

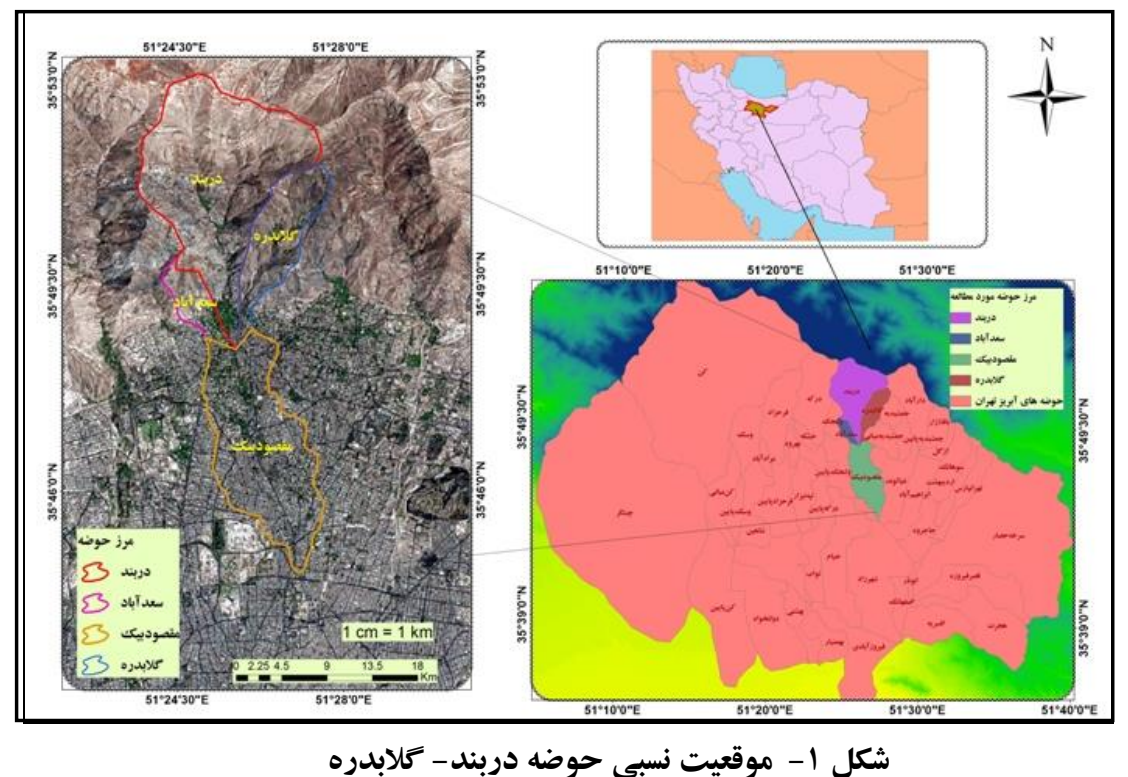

1 SWAT (Soil and Water Assessment Tool) 
19./19.

مواد و روش

در اين ثيزوهش از روشهاى كتابخانهاى، تجربى و توصيفى -تحليلى استفادهشه است. همجنين، جهت دستيابى به اهداف تحقيق از ابزارهايى مانند نقشههاى مدل رقومى ارتفاعى •ب متر (DEM)، كاربرى اراضى، نقشه خاكى و دادهاى هواشناسى از قبيل بارش، حداقل و حداكثر دما، تابش خورشيدى، سرعت باد و رطوبت نسبى كه بهصورت اطلاعات روزانه براى دو دوره حال حاضر و •r سال كذشته استفادهده است. ميزان تغييرات كاربرى اراضى با استفاده از تكنيك سنجشازدور، نقشه

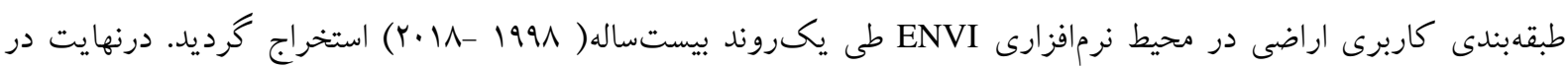
اين يزوهش از مدل SWAT كه يك مدل فيزيكى و نيمه توزيعى مىباشد بهره كرفتهشده است.

مدل SWAT يك مدل جامع در مقياس حوضهاى مىباشد كه توسط سرويس تحقيقاتى كشاورزى آمريكا (USDA-ARS) ارائهده است (Haji Hosseini, Haji Hosseini, Morid, \& Delavar, 2015). اين مدل، براى بيشبينى تأثير روشهاى مديريتى متفاوت بر جريان، رسوب، مواد مغذى و بيلان مواد شيميايى در حوضههايى با خاك، كاربرى اراضى مختلف(تغيير كاربرى) براى دورههاى زمانى طولانى توسعه دادهشه است (Verbeeten \& Barendregt, 2007). در اين مدل بهجاى آن كه از معادلات ركرسيونى جهت توصيف رابطه بين متغيرهاى ورودى و خروجى استفاده نمايد، اطلاعات ويزهاى راجع به هوا، خاك، تويو گرافى، يوشش گياهى و يوشش اراضى در حوضه آبريز دريافت مى كند. اين مدل بهصورت يك الحاقى نرمافزار GIS

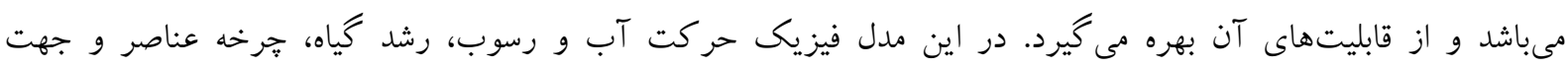
شبيهسازى بهصورت بيوسته در نظر كرفته مىشود. اين مدل حوضه آبريز را به زيرحوضههاى آبريز تقسيم مى كند كه با هر كدام بهعنوان يكى واحد مجزا رفتار مى كند. همجنين زيرحوضهها به بخشهاى ياسخ هيدرولوزى(HRU) ا تقسيم مىشوند كه بخشهايى از زيرحوضهها با يوششها، مديريت و خصوصيات خاك مىباشد. اين مدل از روش عدد منحنى اصلاحشده يا روش نفوذ گرين -اميته جهت محاسبه حجم رواناب سطحى براى هر ياسخ هيدرولوزى استفاده مى كند.

بر اساس نقاط متقاطع لايههاى رسترى يا و كتورى مربوط به كاربرىهاى زمين، انواع خاك ها، زمينشناسى و

زير حوضهها فراهم مى آيند. از نقشهاى خطى مربوط به نهر آبها و شبكههاى زهكشى رودخانها نيز مىتوان براى ايجاد

(Lagacherie, Rabotin, Colin, Moussa, \& Voltz, 2010) استفاده كرد (HRUS)

مدل دمAT در شبيهسازى جرخه هيدرولوزى از معادله توازن هيدرولوزيك( براى هر HRU) زير رابطه( (1) استفاده

مى كند (Goodarzi, Zahabiyoun, Massah Bavani, \& Kamal, 2012).

$\mathrm{SWt}=\mathrm{SWo}+\sum_{\mathrm{i}=1}^{\mathrm{i}}($ Rday $-\mathrm{Qsurf}-\mathrm{Ea}-\mathrm{Wseep}-\mathrm{QgW})$

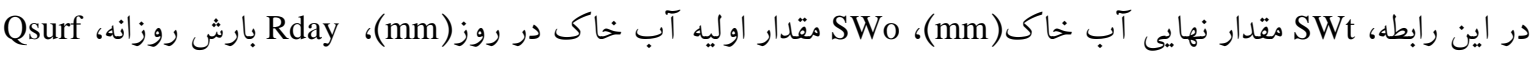
رواناب سطحى، Ea تبخير و تعرق واقعى، Wseep آبى كه از يروفيل خاك به منطقه غيراشباع وارد مىشود و Qgw جريان آب

زيرزمينى خروجى به رودخانه برحسب ميلىمتر مىباشد)(Mengistu, 2009).

يافته هاى يزوهش

جهت استخراج خصوصيات فيزيو گرافى حوضه آبريز دربند-كلابدره از مدل رقومى ارتفاعى باقدرت تفكيك مكانى • 1 متر استفادهشه است. اين اطلاعات شامل محدوده حوضه آبريز، زيرحوضه، نقاط تمركز و خصوصيات فيزيكى حوضه آبريز

\footnotetext{
1 - Hydrologic Response Unit

2 - soil Conservation Service

3 -Green and Ampt
} 


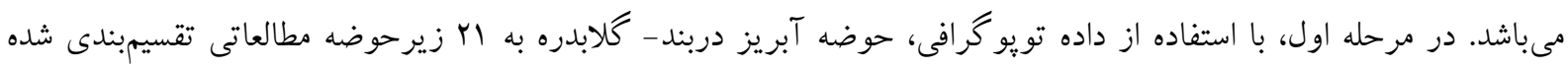

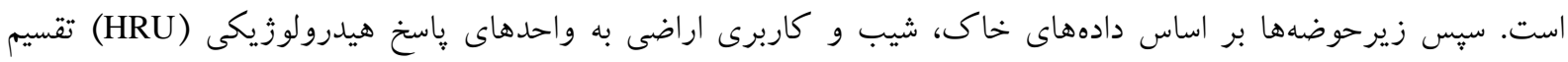

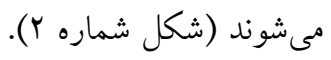

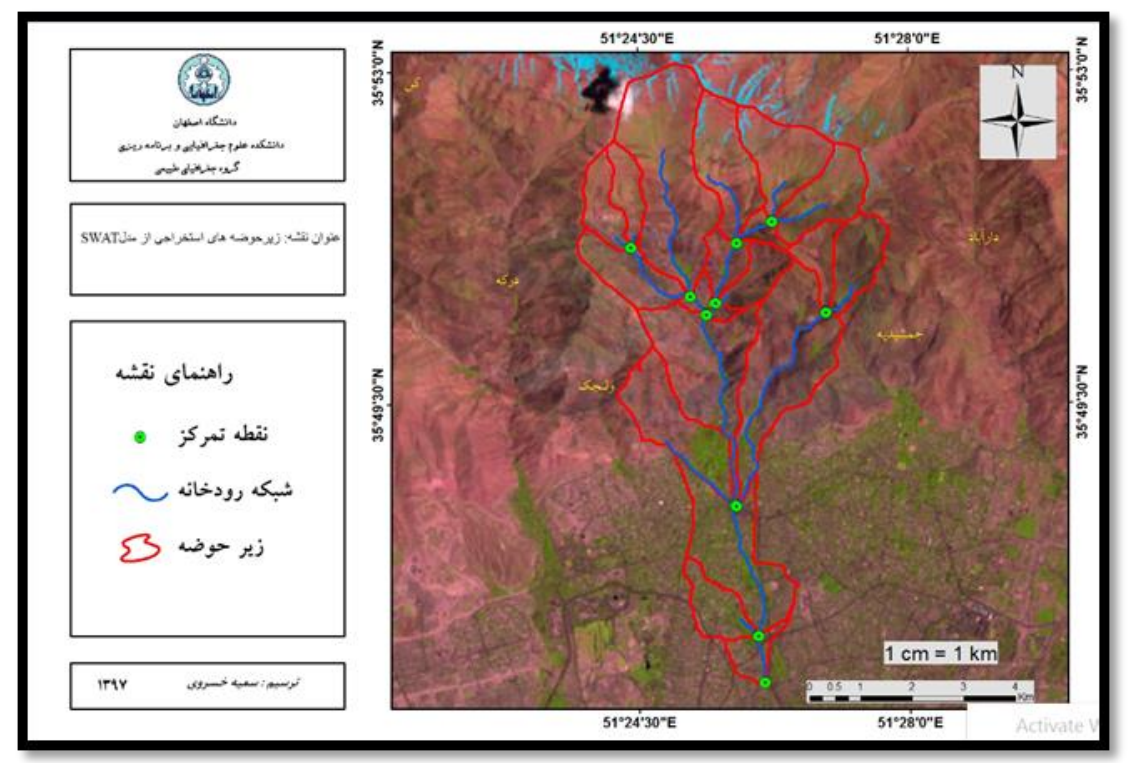

\section{شكل r- زيرحوضه ها و شبكه جريان به همر اه نقاط تمر كز حوضه آبريز دربند- كلابدره،

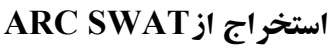

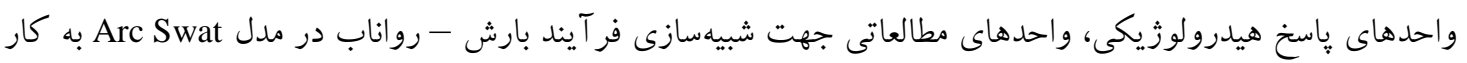

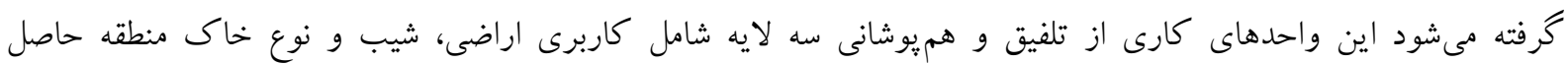

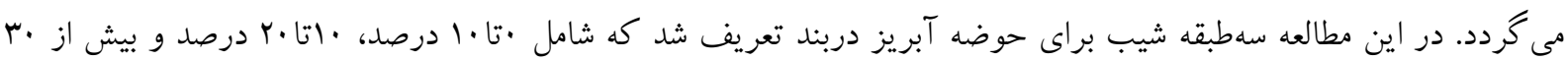
درصد مىباشند(شكل r). اين طبقات شيب نه تنها به تفكيك مكانى بهتر حوضه كمك مى كنند، بلكه براى تشخيص موقعيت

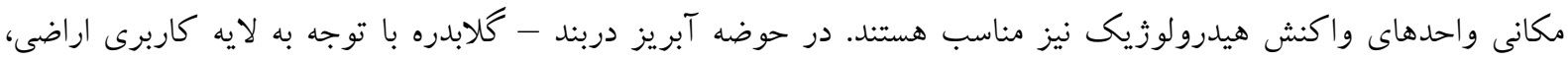

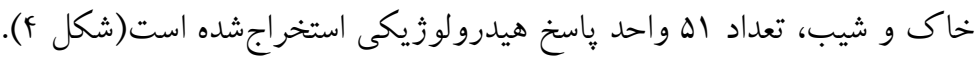

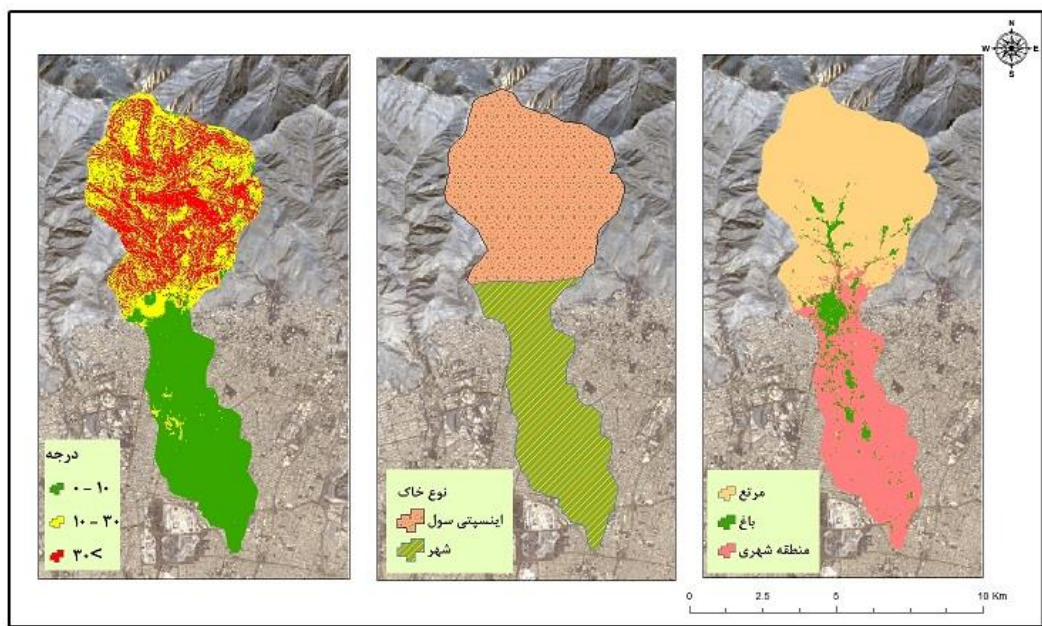

شكل r- نوع كاربرى زمين، خاك و شيب حوضه دربند - كلابدره 


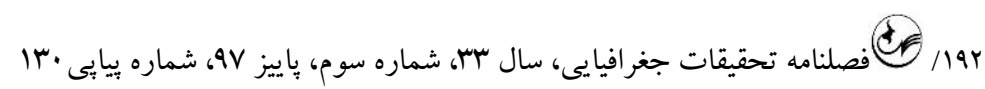

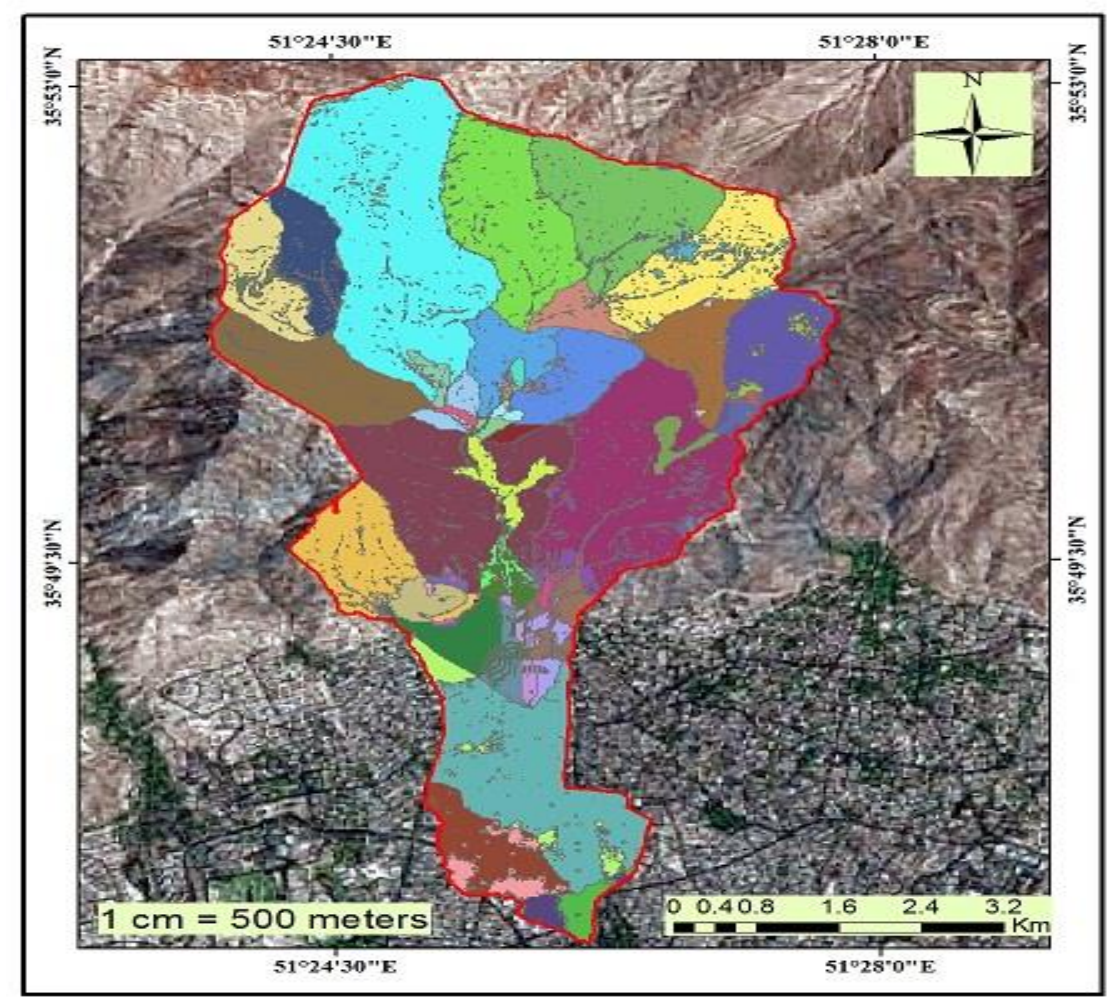

شكل ץ- نقشه HRU استخر اجى توسط مدل ARC SWAT

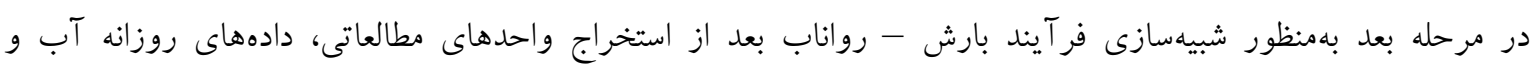

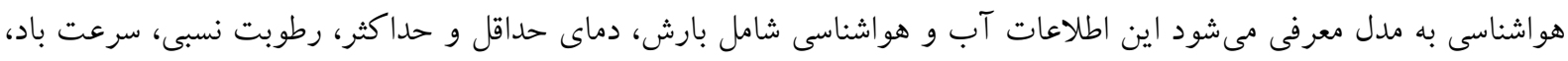

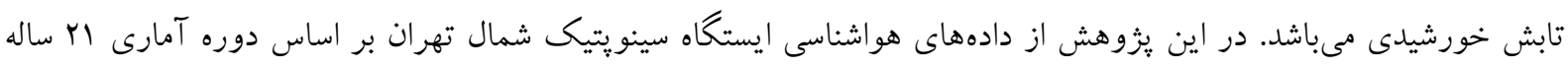

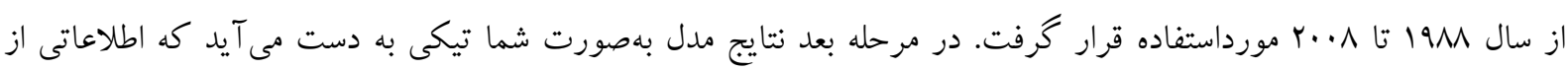

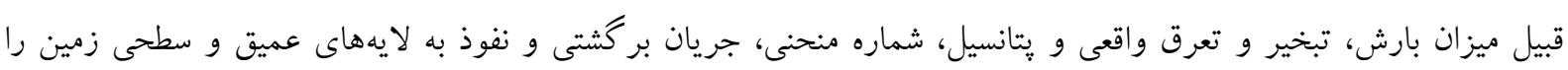
ارائه مى دهد(شكل ه).

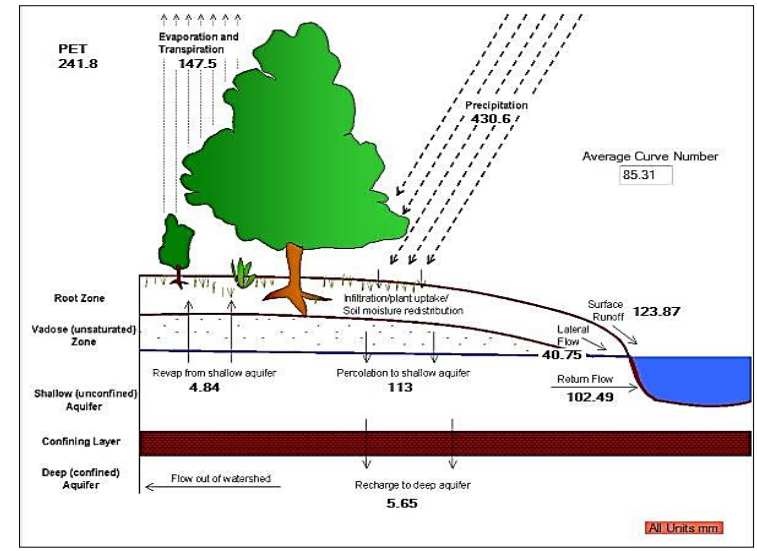

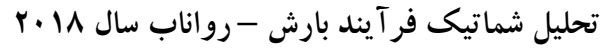

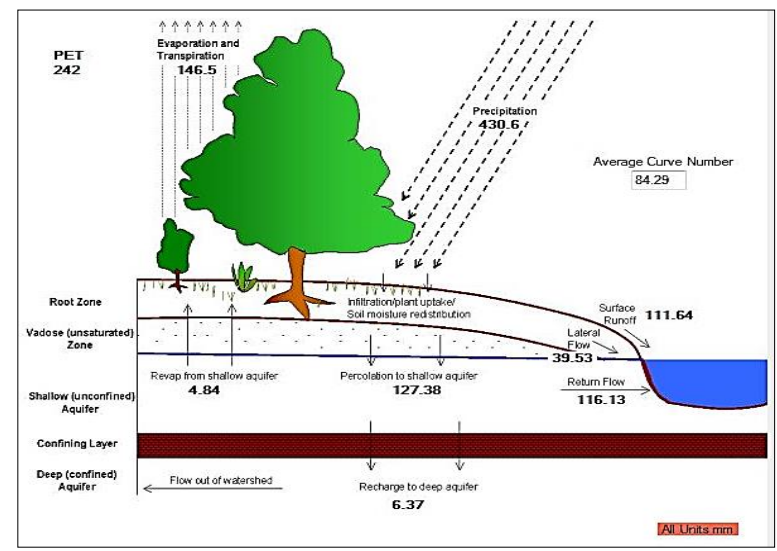

تحليل شماتيك فر آيند بارش - رواناب سال 1991

شكل ه- تحليل شماتيك فر آيند بارش - رواناب حوضه دربند-كلابدره سال هاى 1991 19 و +r 
عناصر مهم جرخه هيدرولوزيكى را بارندگى، رواناب سطحى، تبخير و تعرق، نفوذ و جريانهاى زيرقشرى تشكيل

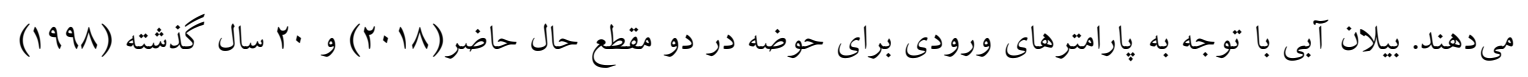

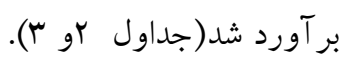

جدول r-نسبت بيلان آبى سال 1991

\begin{tabular}{|c|c|c|c|}
\hline تبخير و تعرق / بارش & رواناب سطحى / جريان كل & جريان يايه / جريان كل & جريان رودخانه /بارش \\
\hline$\cdot / 199$ & $\cdot / V Y$ & $\cdot / K \Lambda$ & .111 \\
\hline \multicolumn{4}{|c|}{ جدول r- نسبت بيلان آبى سال ^| • } \\
\hline ت تبخير و تعرق/ بارش & رواناب سطحى / جريان كل & جريان يايه/ جريان كل & جريان رودخانه/بارش \\
\hline$\cdot / \wedge \Delta$ & $\cdot / \mathrm{VA}$ & $\cdot / r r$ & $\cdot / 1 F$ \\
\hline
\end{tabular}

جداول F و وه مقادير پارامترهاى هيدرولوزيكى را به تفكيك نوع كاربرى اراضى شكل ه وو دور محدوده موردمطالعه

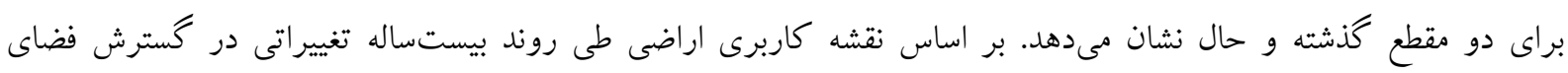

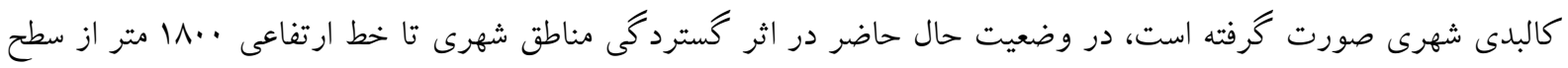

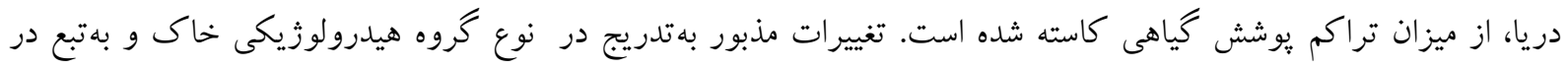

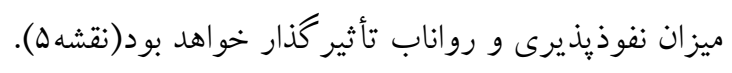

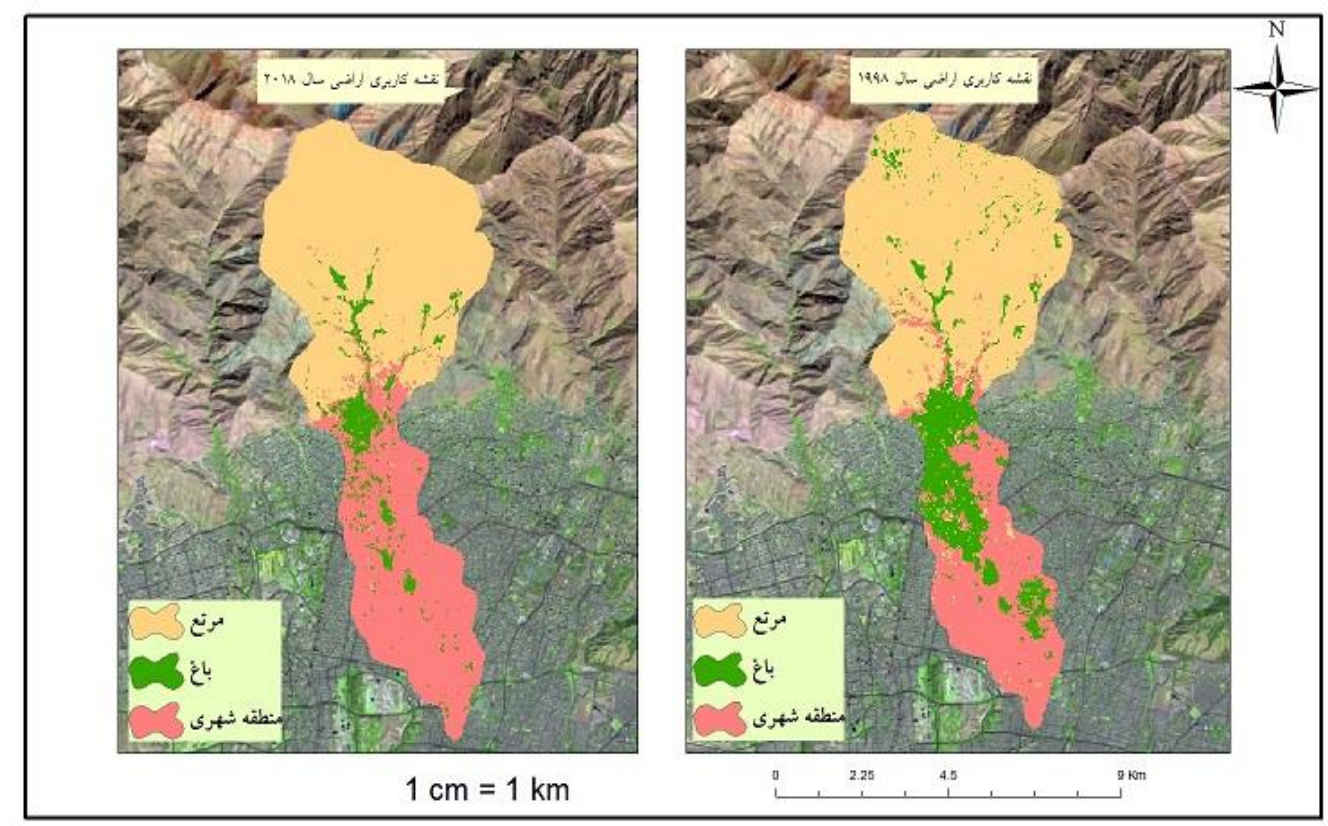

شكل 9- كاربرى اراضى حوضه آبريز دربند - كلابدره براى دوره قبل(1991) و وضع موجود(11 + () 


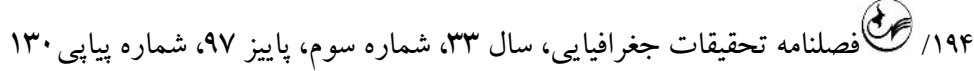

جدول F- مقادير هارامترهاى هيدرولوزيكى به تفكيك نوع كاربرى اراضى سال 1991

\begin{tabular}{|c|c|c|c|}
\hline تبخير و تعرق(از سطح كاربرى) (mm) & رواناب سطحىmm & (شماره منحنى)CN & نوع كاربرى \\
\hline $1 r q / s$. & $I Y / T V$ & VF & مرتع \\
\hline IYN/qT & $r r / s V$ & $V \cdot, \Delta$ & باغات \\
\hline$|f| / v e$ & $1 f / 9 V$ & Vq & منطقه شهرى \\
\hline
\end{tabular}

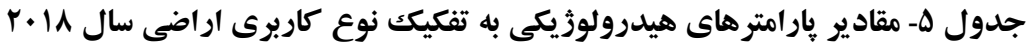

\begin{tabular}{|c|c|c|c|}
\hline (تبخير و تعرقmm) & رواناب سطحى mm & (شماره منحنى)CN & نوع كاربرى \\
\hline IrV & $\mid r / r$ & $\wedge r$ & مرتع \\
\hline Tr & $r_{F}$ & $V V, \omega$ & باغات \\
\hline $119 / \cdot r$ & f. & 98 & منطقه شهرى \\
\hline
\end{tabular}

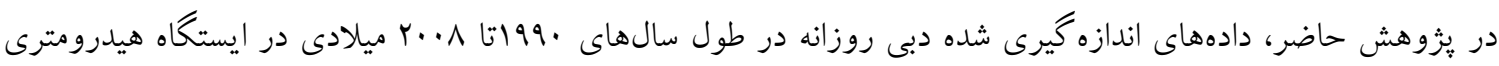

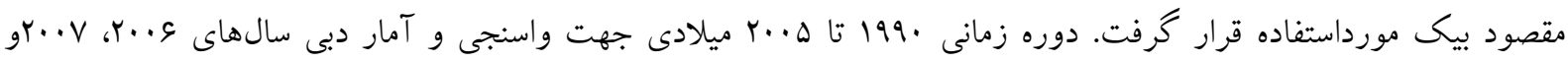

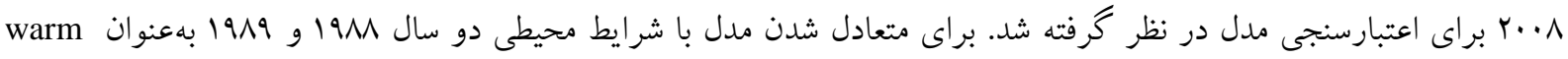

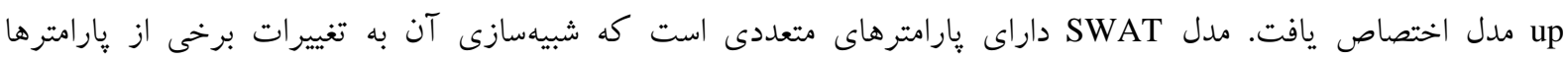

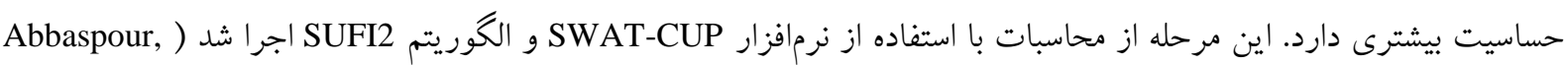

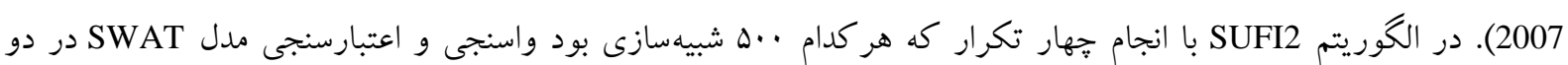

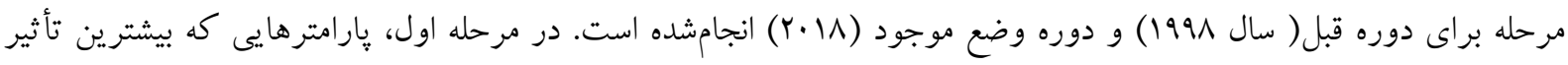

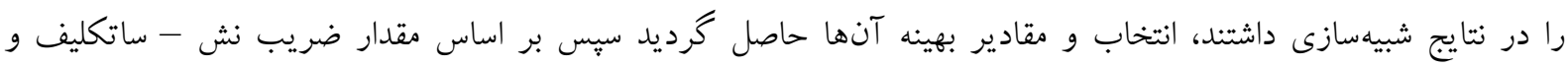

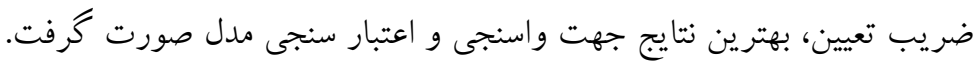


جدول 9-مقادير بارامترهاى تعيينشده براى واسنجى، حداقل، حداكثر و بهينه مقادير حوضه دربند-كلابدره دوره قبل( سال 1991)

\begin{tabular}{|c|c|c|c|c|}
\hline ترتيب حساسيت & ن نام يارامتر & حداقل مقادير & حداكثر مقادير & مقادير بهينه \\
\hline 1 & R_CN2.mgt & $-\because \cdot T \cdot \Delta V G$ & - rq9.44 &. .179191 \\
\hline r & R_SOL_AWC(..).sol & $-1 . \Delta \wedge \Lambda \cdot 1$. & $-\cdot V T \Delta I G T$ & $-1 . \Delta V \Delta \cdot 9 V$ \\
\hline r & R__SOL_K(..).sol & $-\cdot r \ll q \cdot \Delta \Delta$ & - & $\cdot .19 \cdot .10$ \\
\hline i & R_SOL_BD(..).sol & - .q4Frta & 1.TQDTKI & $\cdot . \wedge 1 \wedge \uparrow .$. \\
\hline a & V_ALPHA_BF.gw & $\cdot .1149 \mathrm{VI}$ & $.911 \% 99$ & $\cdot . \Delta T \cdot G \cdot T$ \\
\hline s & V_GW_DELAY.gw & INT...FTY & TrI.VTaTYA & r९Q.r१८१८. \\
\hline $\mathrm{v}$ & V_GWQMN.gw & IrTA.FIFETg & $r r \wedge \Lambda . \Delta \cdot r r q \Delta$ & $r l l \cdot \cdot \Delta \Delta q \cdot \Lambda$ \\
\hline$\wedge$ & V_GW_REVAP.gw & $-\cdot .11 .199$ & $-\cdot .19 r \Delta F$ & $-\cdot \cdot r \mu \cdot r \Delta$ \\
\hline$q$ & V_REVAPMN.gw & $11 \cdot . r 19 \cdot V \Lambda$ & $r \& V \cdot \cdot V \cdots V$ & TFY.GYAVTY \\
\hline 1. & V__RCHRG_DP.gw & - Alvary & $1 . T 19145$ & $1.194 \mathrm{rat}$ \\
\hline 11 & V_ESCO.hru & $\cdot A V T \Delta \cdot T$ & 1. TYADT & $1 . \cdot 194 \mathrm{MA}$ \\
\hline ir & V_EPCO.hru & $\cdot . \wedge \vee \cdots 99$ & $1 . \cdot \Delta \mid f \cdot 1$ & $\cdot .949 . .1$ \\
\hline Ir & V__CH_N2.rte & 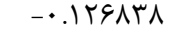 & $\because \Delta \Delta \Delta G Y$ & $-\cdot . I$ TYYA \\
\hline if & V_CH_K2.rte & $r \cdot .99 \Delta \Delta \cdot V$ & VI.TQVTV. & $r \cdot r r \cdot r q 4$ \\
\hline 10 & V__SLSUBBSN.hru & $\because \cdots 99 \Delta$ & $\cdot .11 \% r 90$ & $\cdot .11$ rYFA \\
\hline 18 & V__SMTMP.bsn & $-T .|T \Delta F| \psi$ & .999991 & ( \\
\hline IV & V__SMTMP.bsn & 9. TIFT9 & IT.MFa. $4 \Delta$ & 1. frvkra \\
\hline 11 & V__SMFMX.bsn & -•.DVGFTV & F.ITAQTI & $\cdot .010 \wedge 99$ \\
\hline 19 & V__SMFMN.bsn & •.FTEDFE & $4 . \wedge 94 \wedge 91$ & 1.509119 \\
\hline r. & V__TIMP.bsn & - $.4 \% 110$ & $\cdot .99 \mathrm{TTVq}$ & - . ATGGTY \\
\hline r) & V_ALPHA_BNK.rte & $\because \wedge \uparrow \wedge \Delta \Delta$ & •.DTVqIr & -.ITKFE \\
\hline
\end{tabular}




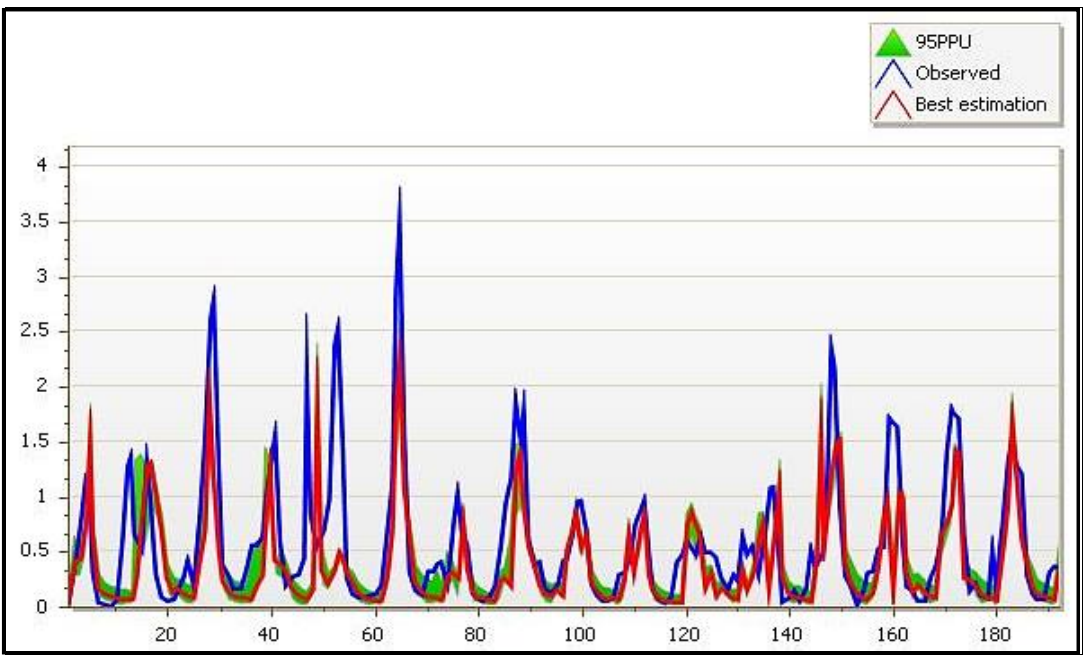

شكل Y- نتايج هيدرو كر افهاى مشاهداتى و شبيهسازىشده در دوره واسنجى

بر يايه زمانى ماهانه، حوضه دربند- كلابدره سال 1991

بعد از بهينهسازى پارامترهاى مورداستفاده در SWAT- CUP ، مقدار ضريب نش - ساتكليف (NS) و ضريب تعيين (R2) سال 1991 در مرحله واسنجى به ترتيب معادل F/F/ • و سF/ • مىباشد براى دوره اعتبارسنجى مقدار ضريب نش - ساتكليف و ضريب

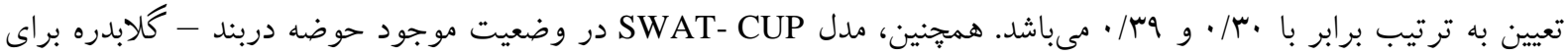

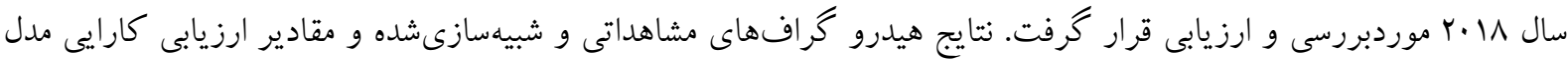

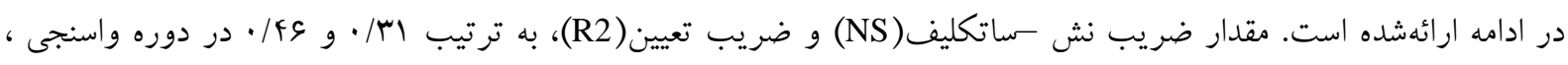

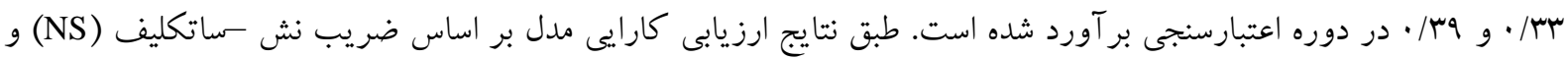

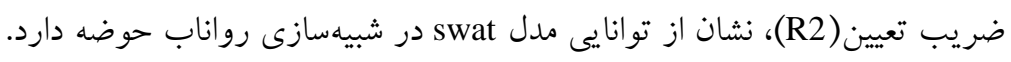

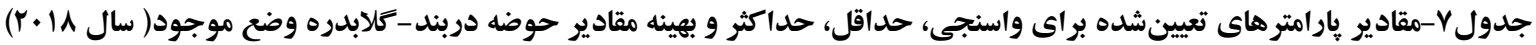

\begin{tabular}{|c|c|c|c|c|}
\hline ترتيب حساسيت & 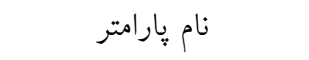 & حداقل مقادير & حداكثر مقادير & مقادير بهينه \\
\hline 1 & A_CN2.mgt & $\wedge r . q \wedge r \cdot \vee \cdot$ & NG.IVVRr. & ND.VT.19T \\
\hline$r$ & R_SOL_AWC(..).sol & 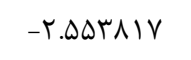 & $-1.4 \wedge 9 \wedge \wedge 1$ & -T.MTTYTY \\
\hline r & R__SOL_K(..).sol & $.991 \wedge 9 \Delta$ & $1 . \Delta 1 \Lambda F \Delta V$ & 1. $९ 99019$ \\
\hline f & R__SOL_BD(..).sol & .919414 & 1.FDIATS & $\cdot .99 \wedge$ \\
\hline a & V_ALPHA_BF.gw & $\cdot . \cdot \cdot \Delta T \& \Delta$ & $1 . \cdot \Delta \Delta \Delta q V$ & $\cdot .949919$ \\
\hline s & V_GW_DELAY.gw & rer.qIVAVY & $\Delta \varsigma 9 . \wedge \Delta \cdot \Delta \wedge \varsigma$ & $f 01.919 .14$ \\
\hline V & V_GWQMN.gw & $|V \Delta \cdot . \wedge \uparrow \Delta \Delta \Lambda|$ & TQ.Y.THIDFT & $r \Delta T \cdot F \cdot \Delta \Delta \mid \Lambda$ \\
\hline$\wedge$ & V_GW_REVAP.gw & $-\cdot r q \cdot \Lambda T I$ & $-\cdot .9 \cdot|r|$ & $-\cdot r \Delta \Lambda F \Lambda$. \\
\hline 9 & V_REVAPMN.gw & MA.TATrFY & $\mid \Delta V \cdot F \Delta \Lambda T \cdot \varphi$ & IFT.DAVATF \\
\hline 1. & V_RCHRG_DP.gw & $\cdot .991 \cdot 49$ & $1 . r \cdot v \cdot \cdot 1$ & $1 . \cdot|r| \cdot 1$ \\
\hline
\end{tabular}


ارزيابى تاثير توسعه كالبدى شهر بر سيستم هاى ... 19V

DOI: 10.29252/geores.33.3. 185

\begin{tabular}{|c|c|c|c|c|}
\hline ترتيب حساسيت & 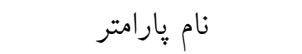 & حداقل مقادير & حداكثر مقادير & مقادير بهينه \\
\hline 11 & V_ESCO.hru & $\cdot \Delta \cdot \Delta \Leftrightarrow 9 \varphi$ & $.9199 \mathrm{VF}$ & $\cdot \Delta \Lambda|\Delta F|$ \\
\hline $1 \%$ & V_EPCO.hru & . ETFTar & - VTaraI &. $.9 V k \cdot 1$ \\
\hline سו & V_CH_N2.rte & $-\cdot \cdot \Delta r V \cdot V$ &. TEVIT &.$\cdot$ IrqTF \\
\hline If & V_CH_K2.rte & FG.GQTKYA & QT.|GTrE| & $\Lambda \cdot .11 T V \Delta F$ \\
\hline 10 & V__SLSUBBSN.hru &..$I T I D F A$ & $\cdot .1 \wedge \vee \cdot 11$ & $\cdot .1$ IFGG \\
\hline Is & V__SMTMP.bsn & - . FNTDSV & $f .1 \% 1911$ & T.Y.NTVG \\
\hline IV & V__SMTMP.bsn & $-\Lambda . \cdot 9 \vee q Y \mathrm{~V}$ & $-f . V \cdot q \varphi v \wedge$ & -V.IfFEIS \\
\hline 11 & V__SMFMX.bsn & T.AF|fF| & G.VIITAK & T.A9TVYA \\
\hline 19 & V_SMFMN.bsn & $-1.71 \cdot 194$ & $r \cdot \cdot \vee \wedge \notin 91$ & - DHIDFG \\
\hline r. & V__TIMP.bsn & $\cdot . \Delta V \& q \vee \Delta$ & $\cdot . q \mu \cdot \vee \wedge \vee$ & $\cdot . \vee 99|V|$ \\
\hline YI & V_ALPHA_BNK.rte & $\cdot \cdots \cdots$ & $\cdot .1 f \cdot r V V$ & • • \\
\hline
\end{tabular}

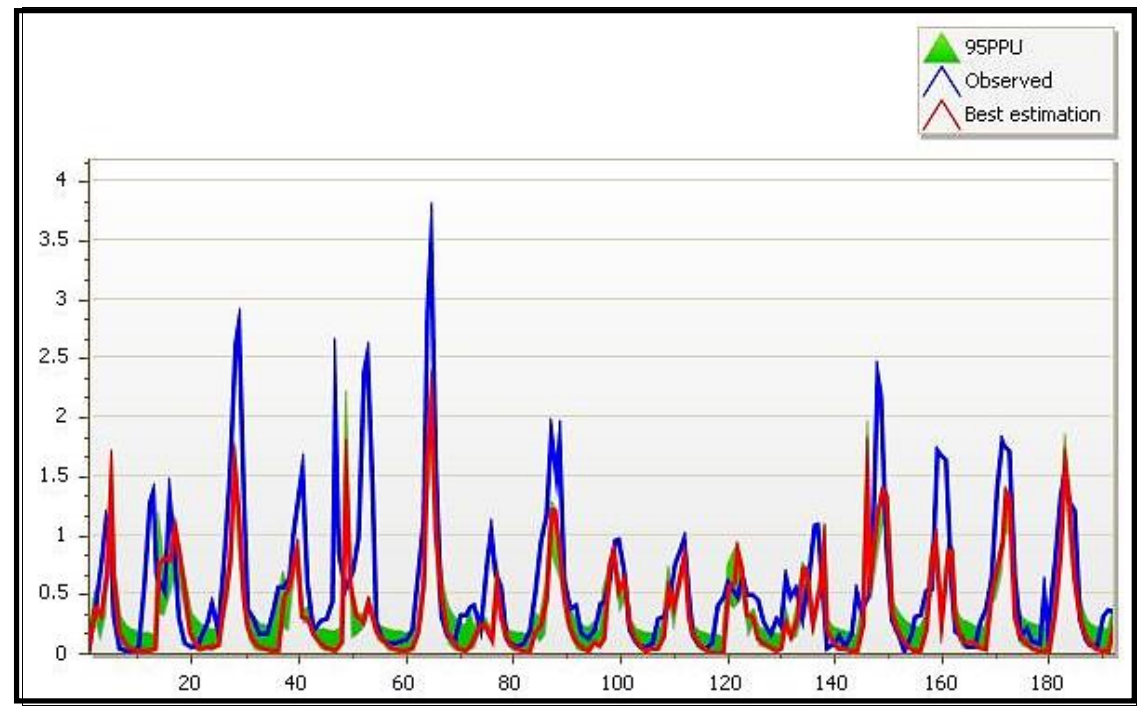

شكل1^-نتايج هيدروكرافهاى مشاهداتى و شبيهسازىشده در دوره واسنجى بر پايه

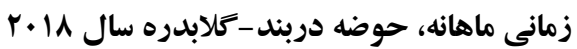

فعاليتهاى كاربرى بشر بهطور بنيادى تغيير هيدروزئومورفوزى رودخانها را به دنبال دارد. در دوران اخير،

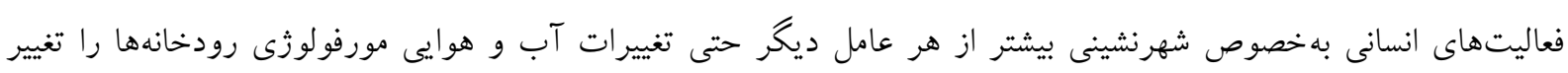

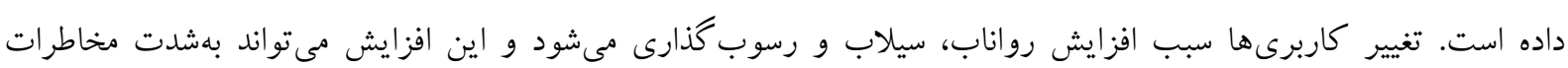

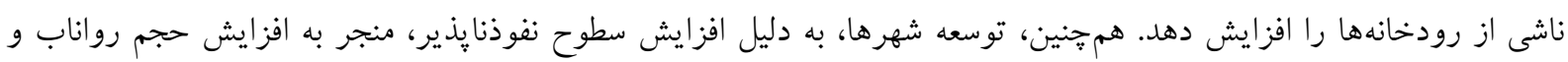

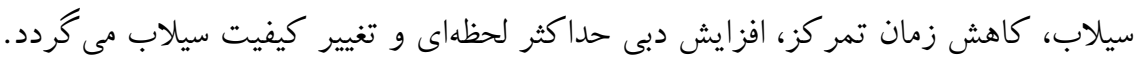




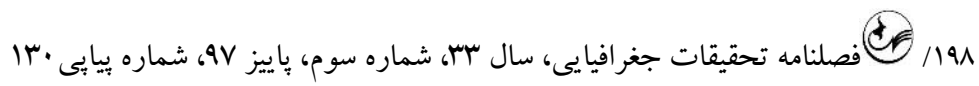

در محدوده موردمطالعه، تنوع و گوناگونى ساختوساز و ساختارهاى شهرى، وجود موقعيتهاى مناسب و بافتهاى

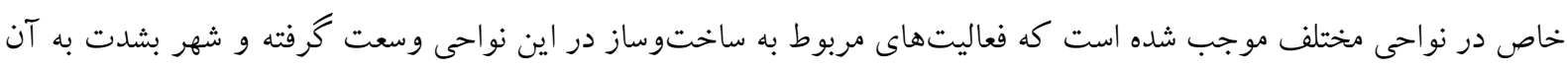

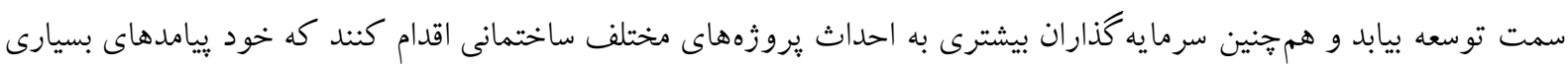
بر روى تغييرات سيستم هاى زئومورفيك ازجمله سيستم هاى رودخانهاى را به دنبال دارد. از طرف ديخر در زئومورفولوزى ما با فرايندها سرو كار داريم و در اين تغييرات خواستهايم تأثيرات هيدروزئومورفولوزى ندي

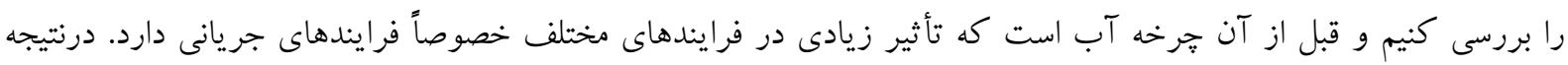

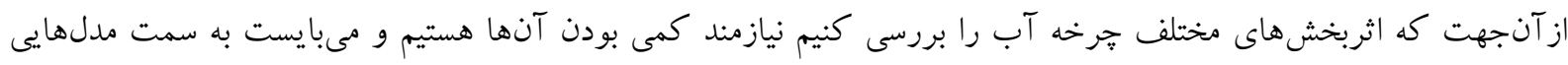

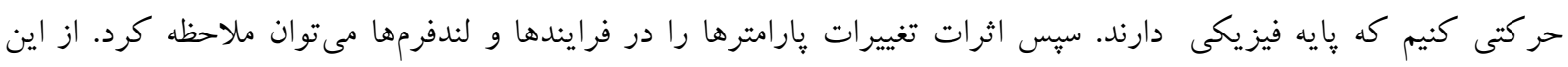

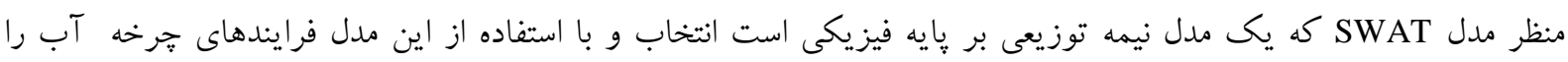
مى توان كمى كرد. نتيجه گيرى

طبق نتايج حاصل از شبيهسازى فر آيند بارش - رواناب ، ميانگين بارش در حوضه آبريز دربند - گكلابدره بر اساس داده

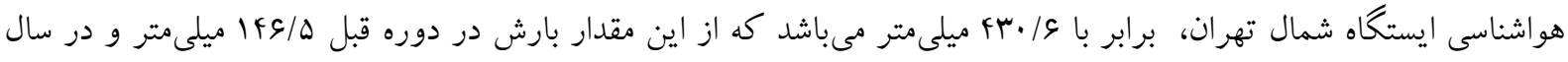

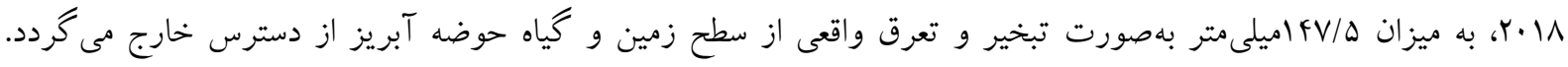

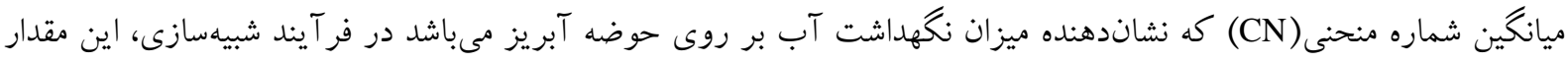

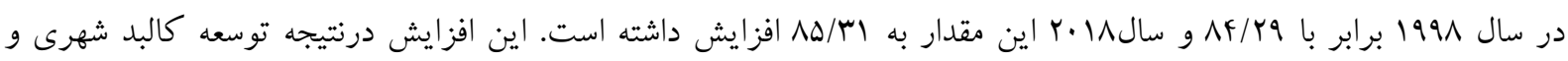

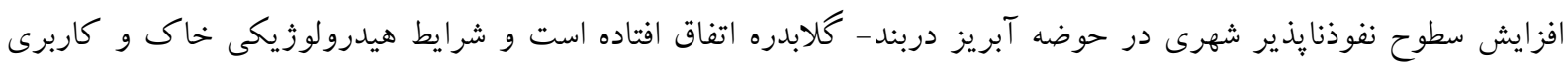

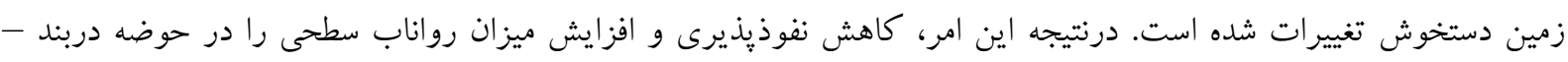

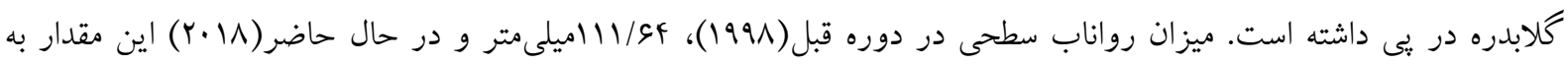

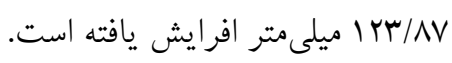
هم هنين ميزان جريان باز گشتى به حوضه آبريز، نفوذ به آبخوانهاى سطحى و عميق نيز روند كاهشى و منفى را به همراه

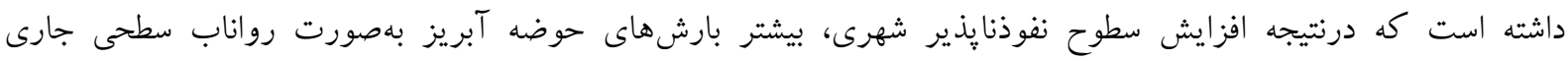

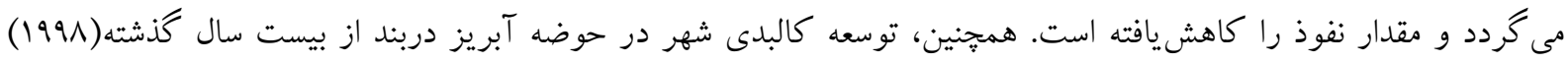

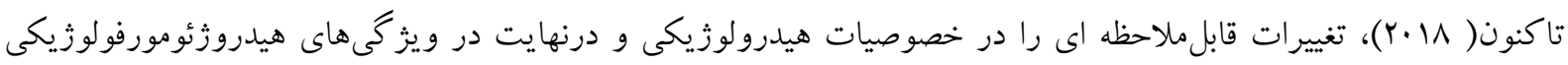

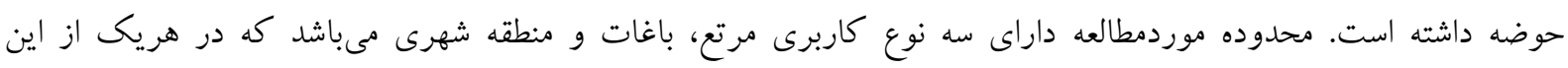

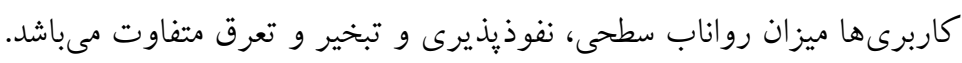

به دليل شرايط ذكرشده در ابتداى بحث محدوده موردمطالعه نسبت به سه دهه كذشته برتراكم و به سمت كاربرى هاى

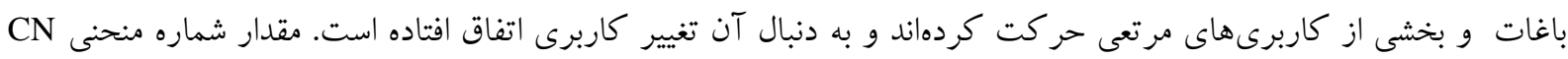

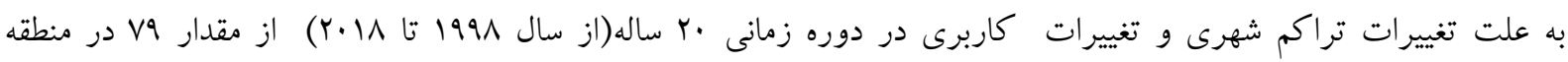

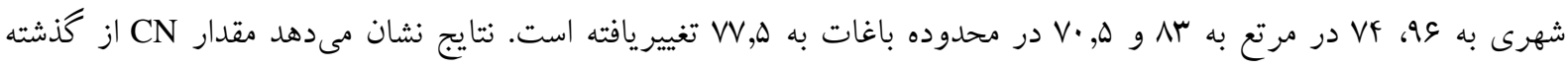

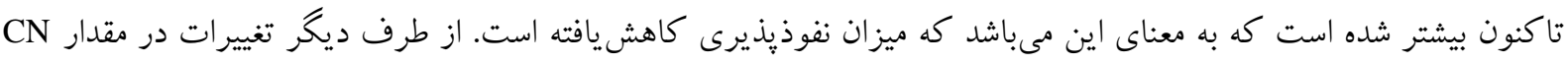

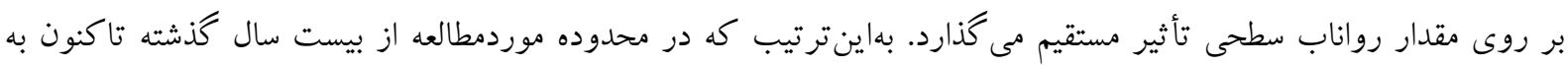

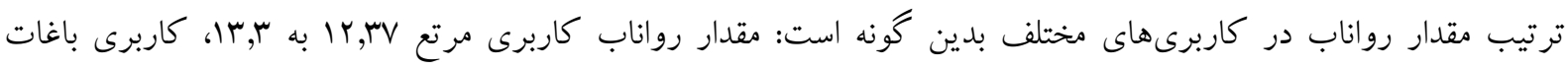


ارزيابى تاثير توسعه كالبدى شهر بر سيستم هاى ... / 199

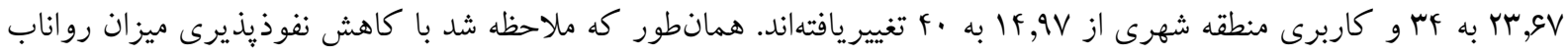
سطحى بشدت افزايش يافت كه خود در محدوده موردمطالعه مخاطرات جدى را به دنبال دارد. همجنين شاخص تبخير و تعرق هم بشدت تحت تأثير مىباشد بدينصورت كه از 1991 تاكنون 11 1.ب، ميزان تبخير و تعرق از سطح كاربرى در كاربرى مرتع

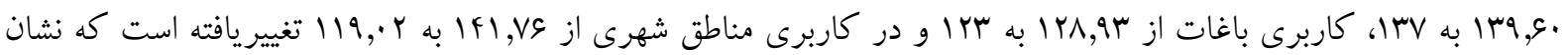
مىدهد ميزان تبخير و تعرق نسبت به كذشته به دليل از بين رفتن زوشش كياهى در محدوده و تغييرات كاربرى كاهش داشته

مدل بكWT بكار كرفتهشده در اين تحقيق و ارزيابى دقت خيلى مهم مىباشد و از آن نظر كه مىخواهد داده شبيهسازىشده را بر اساس پارامترهايى مثل رواناب با دادههاى واقعى منطبق كند درنتيجه پارامترهاى مختلفى كه در گير اين

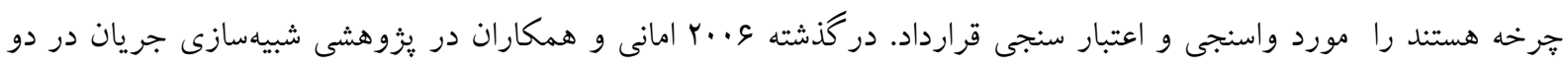
زيرحوضه ماهى دشت و سنجابى از زيرحوضههاى رودخانه كارون را با استفاده از مدل سوات در دو مرحله واسنجى و اعتبار سنجى انجام دادند كه نتايج حاكى از كارايى مناسب مدل در حوضه مذكور بود. كه واسنجى مدل مقدار ضريب R2 شبيهسازى

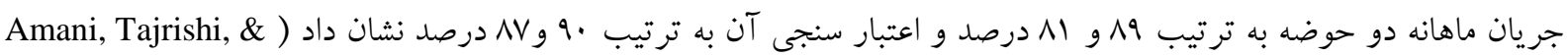

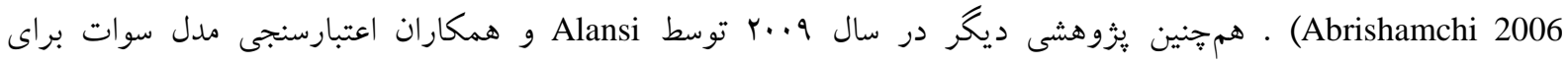
شبيهسازى و بيشبينى جريان آبراههاى در مالزى را انجام دادهاند. كه در آن نتايج شبيهسازى در مرحله واسنجى براى پايه زمانى ماهانه با استفاده از ضرايب كارايى R2 و نش- ساتكايف به ترتيب هو٪ و rو٪٪ و در مرحله اعتبارسنجى سو٪ و rو٪ به دست آمد. درنهايت مىبايست خاطرنشان كرد مدل سوات در تحقيق آنها توانست بهخوبى در تشخيص زيرحوضههاى داراى شرايط

بحرانى مورداستفاده قرار گيرد (Alansi, Amin, Abdul Halim, Shafri, \& Aimrun, 2009).

سهم نويسند گان: سميه خسروى (نويسنده اول)، يزوهشخر اصلى ( •و٪)، مز گان انتظارى (نويسنده دوم)، يزوهشكر كمكى

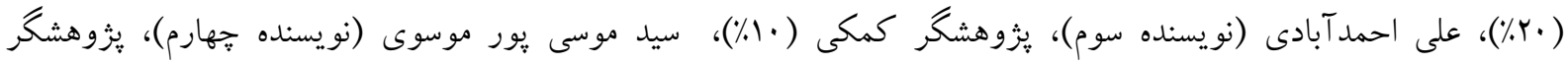

A Detailed Plan of the Tehran 1 Region. (2007). Department of Management and Planning of Tehran Urban Development Plans, Ministry of Housing and Urban Development Retrieved from Tehran Municipality. (Persian)

Abbaspour, K. C. (2007). User manual for SWAT-CUP, SWAT calibration and uncertainty analysis programs. Swiss Federal Institute of Aquatic Science and Technology, Eawag, Duebendorf, Switzerland .

Agha Beigi, M., \& Lesani, M. (2008). Runoff analysis of the city of Mashhad using the interpretation of satellite images and the proposed methods for controlling and reducing urban runoff. Paper presented at the First National Engineering Conference of Consumers, Mashhad, Mashhad municipality. (Persian)

Ahmad Abadi, A., Kiani, T., \& Ghafoorpoor Anbaran ,P. (2017). The effects of watershed management practices in Hydro-geomorphological characteristics in Anbaranchay watershed. The Journal of Spatial Planning, 21(2), 35-55. (Persian)

Alansi, A., Amin, M., Abdul Halim, G., Shafri, H., \& Aimrun, W. (2009). Validation of SWAT model for stream flow simulation and forecasting in Upper Bernam humid tropical river basin, Malaysia. Hydrology and Earth System Sciences Discussions, 6(6), 7581-7609. [DOI:10.5194/hessd-6-75812009]

Amani, N., Tajrishi, M., \& Abrishamchi , A. (2006). Simulation of stream flow by applying SWAT model and GIS. Paper presented at the Seventh International Conference on River Engineering, Ahvaz, Shahid Chamran University. (Persian) 


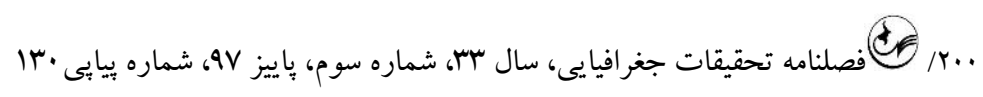

Booth, D. B., Karr, J. R., Schauman, S., Konrad, C. P ,.Morley, S. A., Larson, M. G., \& Burges, S. J. (2004). Reviving urban streams: Land use, hydrology, biology, and human behavior. Journal of the American Water Resources Association, 40(5), 1351-1364. [DOI:10.1111/j.1752-1688.2004.tb01591.x]

Chin, A. (200 .('Urban transformation of river landscapes in a global context. Geomorphology, 79(3), 460-487. [DOI:10.1016/j.geomorph.2006.06.033]

Chin, A., O'Dowd, A. P., \& Gregory, K. J. (2013). 9.39 urbanization and river channels. In J. F. Shroder (Ed.), Treatise on Geomorphology (pp. 809-827). San Diego: Academic Press.

Findlay, S. J., \& Taylor, M. P. (2006). Why rehabilitate urban river systems? Area, 38(3), 312-325 .

Ghanavati, E., Safari, A., Karam, A., Najafi, E., \& Jahandar, G. (2016). Hydrogeomorphological characteristics of Tehran metropolitan watersheds. Journal of Hydrogeomorphology, 2(6), 33-54. (Persian)

Goodarzi, M. R., Zahabiyoun, B., Massah Bavani, A. R., \& Kamal, A. R. (2012). Performance comparison of three hydrological models SWAT, IHACRES and SIMHYD for the runoff simulation of Gharesou basin. Journal of Water and Irrigation Managemant (Journal of Agriculture), 2(1), 25-40. [DOI:10.22059/JWIM.2012.25090]. (Persian)

Haji Hosseini, H. R., Haji Hosseini, M. R., Morid, S., \& Delavar, M. (2015). Hydrological simulation of the upper hirmand transboundary catchment using SWAT model. Journal of Science and Technology of Agriculture and Natural Resources, 19(72), 255-268. [DOI:10.18869/acadpub.jstnar.19.72.22]. (Persian)

Hardison, E. C., O’Driscoll, M .A., DeLoatch, J. P., Howard, R. J., \& Brinson, M. M. (2009). Urban land use, channel incision, and water table decline along coastal plain streams, North Carolina. Journal of the American Water Resources Association, 45(4), 1032-1046. [DOI: 10.1111/j.1752-1688.2009.00345.x]

Hossein zadeh, M., \& Esmaeli, R. (2015). River geomorphology (First ed.). Tehran: Shahid Beheshti University. (Persian)

Hossein Zadeh, R., \& Jahadi Toroghi, M. (2007). The effects of urbanization on the natural drainage patterns and the increase of urban floods: Case study Metropolis of Mashhad-Iran. Geographic Research, 39(61), 145-159. (Persian)

Hosseini, M., Ghafouri, A. M., Amin, M. S. M., Tabatabaei, M. R., Goodarzi, M., \& Abde Kolahchi, A. (2012). Effects of land use changes on water balance in Taleghan catchment, Iran. Journal of Agricultural Science and Technology, 14(5), 1161-1174 .

Hosseini, M., \& Mokarian, Z. (2014). Estimation of ground water runoff by SWAT model in Golgol catchment. Journal of Watershed Engineering and Management, $8(1), \quad 80-92$. [DOI:10.22092/IJWMSE.2016.105976]. (Persian)

Lagacherie, P., Rabotin, M., Colin, F., Moussa, R., \& Voltz, M. (2010). Geo-MHYDAS: A landscape discretization tool for distributed hydrological modeling of cultivated areas. Computers \& Geosciences, 36(8), 1021-1032. [DOI:10.1016/j.cageo.2009.12.005]

Lin, Y.-P., Lin, Y.-B., Wang, Y.-T., \& Hong, N.-M. (2008). Monitoring and predicting land-use changes and the hydrology of the urbanized Paochiao watershed in Taiwan using remote sensing data, urban growth models and a hydrological model. Sensors, 8(2), 658-680. [DOI:10.3390/s8020658]

Mengistu, K. T. (2009). Watershed hydrological responses to changes in land use and land cover, and management practises at Hare Watershed, Ethiopia, engineering and machine engineering, University Siegen. Retrieved from http://dokumentix.ub.uni-siegen.de/opus/volltexte/2009/420/

Najafi, E. (2015). Geomorphologic modeling of bridges in urban areas (case study: Tehran metropolis). (PhD Thesis), Kharazmi University. (Persian)

Navratil, O., Breil, P., Schmitt, L., Grosprêtre, L., \& Albert, M. B. (2013). Hydrogeomorphic adjustments of stream channels disturbed by urban runoff (Yzeron River basin, France). Journal of Hydrology, 485, 24-36. [DOI:10.1016/j.jhydrol.2012.01.036]

Royall, D. (2013). 13.3 Land-Use Impacts on the Hydrogeomorphology of small watersheds. In J. F. Shroder (Ed.), Treatise on Geomorphology (pp. 28-47). San Diego: Academic Press.

Saberi, A. (1995). Investigating the effects of urban development changes in northern Tehran to provide methods for controlling and managing flood. (Master's Thesis), Tarbiat Modares University. (Persian .)

Taniguchi, K. T., \& Biggs, T. W. (2015). Regional impacts of urbanization on stream channel geometry: A case study in semiarid southern California. Geomorphology, 248, 228-236. [DOI:10.1016/j.geomorph.2015.07.038] 
ارزيابى تاثير توسعه كالبدى شهر بر سيستم هاى ... / ا

DOI: 10.29252/geores.33.3. 185

Verbeeten, E., \& Barendregt, A. (2007). The impacts of climate change on hydrological services provided by dry forest ecosystems in West Africa .Paper presented at the 4th International SWAT Conference, Netherlands .

Vietz, G. J., Walsh, C. J., \& Fletcher, T. D. (2015). Urban hydrogeomorphology and the urban stream syndrome: Treating the symptoms and causes of geomorphic change. Progress in Physical Geography: Earth and Environment, 40(3), 480-492 .

Zamanzadeh, S. M., Yamani, M., \& Bani Safar, M. (2013). Erosion of the bed and river bank due to the harvesting of river materials. Case study: Zaringal river, Golestan Province. Paper presented at the Second International Conference on Environmental Risks, Tehran, Kharazmi University. (Persian) 